\title{
On the interaction between marine boundary layer cellular cloudiness and surface heat fluxes
}

\author{
J. Kazil ${ }^{1,2}$, G. Feingold ${ }^{2}$, H. Wang ${ }^{3}$, and T. Yamaguchi ${ }^{1,2}$ \\ ${ }^{1}$ Cooperative Institute for Research in Environmental Sciences (CIRES), University of Colorado, Boulder, Colorado, USA \\ ${ }^{2}$ Chemical Sciences Division, Earth System Research Laboratory, NOAA, Boulder, Colorado, USA \\ ${ }^{3}$ Pacific Northwest National Laboratory, Richland, WA, USA
}

Correspondence to: J. Kazil (jan.kazil@noaa.gov)

Received: 5 June 2013 - Published in Atmos. Chem. Phys. Discuss.: 15 July 2013

Revised: 18 November 2013 - Accepted: 21 November 2013 - Published: 2 January 2014

\begin{abstract}
The interaction between marine boundary layer cellular cloudiness and surface fluxes of sensible and latent heat is investigated. The investigation focuses on the nonprecipitating closed-cell state and the precipitating open-cell state at low geostrophic wind speed. The Advanced Research WRF (Weather Research and Forecasting) model is used to conduct cloud system-resolving simulations with interactive surface fluxes of sensible heat, latent heat, and of sea salt aerosol, and with a detailed representation of the interaction between aerosol particles and clouds. The mechanisms responsible for the temporal evolution and spatial distribution of the surface heat fluxes in the closed- and open-cell state are investigated and explained. It is found that the closed-cell state imposes its horizontal spatial structure on surface air temperature and water vapor, and, to a lesser degree, on the surface sensible and latent heat flux. The responsible mechanism is the entrainment of dry, free tropospheric air into the boundary layer. The open-cell state is associated with oscillations in surface air temperature, water vapor, and in the surface fluxes of sensible heat, latent heat, and of sea salt aerosol. Here, the responsible mechanism is the periodic formation of clouds, rain, and of cold and moist pools with elevated wind speed. Open-cell cloud formation, cloud optical depth and liquid water path, and cloud and rain water path are identified as good predictors of the horizontal spatial structure of surface air temperature and sensible heat flux, but not of surface water vapor and latent heat flux. It is shown that the open-cell state creates conditions conducive to its maintenance by enhancing the surface sensible heat flux. The open-cell state also enhances the sea salt flux relative to the closed-cell state. While the open-cell state under consid-
\end{abstract}

eration is not depleted in aerosol and is insensitive to variations in sea salt fluxes, in aerosol-depleted conditions, the enhancement of the sea salt flux may replenish the aerosol needed for cloud formation and hence contribute to the maintenance of the open-cell state. Spatial homogenization of the surface fluxes is found to have only a small effect on cloud properties in the investigated cases.

\section{Introduction}

Stratocumulus clouds over the oceans play an important role for Earth's climate owing to their large areal coverage and the high contrast in albedo between the bright clouds and the dark sea underneath (Wood, 2012). Regular patterns in horizontal cloud structure, such as bands and several types of cells, first identified in satellite images (Krueger and Fritz, 1961; Agee, 1984), reflect different states of boundary layer dynamics (Atkinson and Zhang, 1996). This work focuses on two of these states, the closed-cell state and the precipitating open-cell state. The closed-cell state exhibits little or no surface rain and a cloud fraction close to unity. Its cellular structure is relatively stationary in character (Koren and Feingold, 2013), and is driven by cloud-top radiative cooling that produces narrow downdrafts surrounding broader updrafts (Shao and Randall, 1996). This circulation pattern creates high optical depths in broad cell centers and reduced optical depths in the narrow periphery. In contrast, the precipitating open-cell state exhibits a low cloud fraction in broad, optically thin cell centers, surrounded by narrow rings of optically thick and sometimes heavily drizzling 
clouds (Stevens et al., 2005; Van Zanten and Stevens, 2005; Sharon et al., 2006). The dynamics is non-stationary and periodic in character, with oscillations driven by the formation of negative buoyancy in updrafts forming at convergence zones of three adjacent open cells (Feingold et al., 2010). Evaporation of rain below cloud base, which cools and eventually reverses the updrafts (Xue et al., 2008; Wang and Feingold, 2009a), has been identified as a key forcing of the open-cell state (Savic-Jovcic and Stevens, 2008). The resulting downdrafts lead to the formation of cold and moist pools at the surface, as well as to surface wind divergence (Jensen et al., 2000; Comstock et al., 2005; Stevens et al., 2005; Comstock et al., 2007; Wood et al., 2011).

The closed- and the open-cell state derive their relevance to the climate system from the difference in their cloud fraction and cloud radiative forcing, and from potential transitions between the two states. Rain at cloud base is thought to be a necessary (Stevens et al., 2005) but not a sufficient (Wood et al., 2011) condition for the transition from closed to open cells. However, even very weak rain (few tenths of $\mathrm{mm} \mathrm{d}^{-1}$ ) reaching the surface can initiate open-cell formation (Wang and Feingold, 2009a). Observations indicate that the reverse transition, from open- to closed-cells, also occurs in nature, and requires suppression of rain by enhanced aerosol concentrations such as from ship emissions (Goren and Rosenfeld, 2012), although simulations have not yet reproduced this phenomenon (Wang and Feingold, 2009b), hinting at the importance of environmental controls.

A multitude of mechanisms can lead to the development of rain in closed cells, and hence to open-cell formation, including perturbations in boundary layer moisture, temperature, aerosol concentration, and surface sensible and latent heat fluxes (Wang et al., 2010). Wang et al. (2010) found that large increases in surface sensible heat flux and/or latent heat flux are effective in triggering rain and the formation of open cells. Deepening of the boundary layer can also initiate rain formation and thus the transition from closed to open cells (Mechem et al., 2012). The causative effect of an increased surface sensible heat flux and of boundary layer deepening on the formation of rain and open cells is the basis of a proposed mechanism for the breaking of marine stratocumuli into trade wind cumuli (Rosenfeld et al., 2006): as the stratocumulus decks along the western coasts of continents are advected by the geostrophic flow towards the Equator, hence towards warmer water and reduced subsidence, the associated increase in surface sensible heat flux and deepening of the boundary layer would result in the formation of rain, open cells, and eventually of trade wind cumuli. The prevailing mechanism for the evolution from stratocumulus to trade wind cumulus is thought to be decoupling, which occurs when the stratocumulus deck is advected over warmer water, resulting in a higher surface sensible heat flux, a deepening of the boundary layer, increased entrainment of free tropospheric air, and a higher surface latent heat flux, with or without rain (Krueger et al., 1995; de Roode and Duynkerke, 1997; Bretherton and Wyant, 1997).

In this work, the interaction between the closed- and opencell state with the surface fluxes of sensible and latent heat is investigated. The investigation is motivated by the presence of cold and moist pools with surface wind divergence in the open-cell state, which have the potential to modify the surface flux of sensible and latent heat and of sea salt aerosol, relative to the closed-cell state. Such a modification could represent a feedback loop in the open-cell state, via the effects of surface heat and sea salt aerosol fluxes on cloud processes. The text is organized as follows: Sect. 2 gives a brief overview of the model used in the investigation. The simulations are described in Sect. 3, followed by a discussion of the results in Sect. 4. Conclusions are given in Sect. 5. Conventions used throughout this work include the definition of liquid water path as the vertically integrated mass of cloud and rain water; cloud fraction is the fractional area with a liquid water path $>10 \mathrm{~g} \mathrm{~m}^{-2}$.

\section{Model}

The Advanced Research WRF (Weather Research and Forecasting) model (ARW) (Skamarock et al., 2008), with chemical and aerosol processes (WRF/Chem, Grell et al., 2005), and the modifications described in Kazil et al. (2011), is used. For the purpose of this work, all chemical and most aerosol processes are disabled in the model, with the exception of sea salt aerosol emissions (Clarke et al., 2006), aerosol water uptake (Petters and Kreidenweis, 2007), activation of aerosol to cloud droplets, cloud processing of aerosol via collisioncoalescence, and aerosol dry and wet deposition. Perpetual night is assumed by disabling short-wave radiation in order to isolate the processes under investigation from variability introduced by the diurnal cycle. Long-wave radiation is parameterized using the Community Atmosphere Model scheme (CAM 3.0, Collins et al., 2004). The sub-grid scale eddy viscosity and diffusivity are calculated with the turbulence kinetic energy scheme of Deardorff (1972) to represent unresolved turbulence.

The ARW model calculates surface sensible $\left(H_{\mathrm{S}}\right)$ and latent $\left(H_{\mathrm{L}}\right)$ heat fluxes interactively from surface quantities. $H_{\mathrm{S}}$ and $H_{\mathrm{L}}$ are proportional to the horizontal wind speed $|\boldsymbol{U}+\boldsymbol{V}|$ at the lowest model level $(1=1)$, and to the surface air temperature and humidity difference, respectively:

$H_{\mathrm{S}} \propto\left(T_{\text {sea surface }}-T_{\mathrm{l}=1}\right)|\boldsymbol{U}+\boldsymbol{V}|_{1=1}$,
$H_{\mathrm{L}} \propto\left(Q_{\text {sea surface }}-Q_{\mathrm{l}=1}\right)|\boldsymbol{U}+\boldsymbol{V}|_{\mathrm{l}=1}$.

$\boldsymbol{U}$ and $\boldsymbol{V}$ are the component vectors of the horizontal wind speed in the west-east and south-north directions, respectively. The proportionality coefficients are calculated using similarity theory (Skamarock et al., 2008, 8.3.1). $T_{l=1}$ and $Q_{1=1}$ are the air temperature and water vapor mixing ratio of 

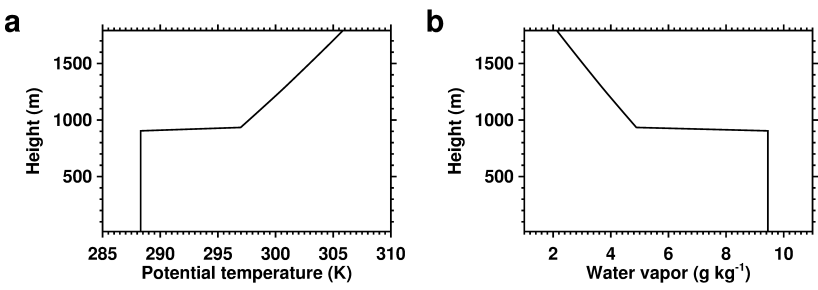

Fig. 1. Initial potential temperature and total water (as water vapor) profiles. In the boundary layer, potential temperature is initialized with $288.3 \mathrm{~K}$, and total water with $9.45 \mathrm{~g} \mathrm{~kg}^{-1}$.

air at the lowest model level, and will be referred to as surface air temperature and surface water vapor, respectively, throughout this work. $T_{\text {sea surface }}$ is the sea surface temperature, $Q_{\text {sea surface }}$ is the saturation water vapor mixing ratio of air at this temperature. The $10 \mathrm{~m}$ horizontal surface wind speed $|\boldsymbol{U}+\boldsymbol{V}|_{10 \mathrm{~m}}$ is used in the calculation of the sea salt aerosol flux (Clarke et al., 2006).

The components $U=|\boldsymbol{U}|$ and $V=|\boldsymbol{V}|$ of the horizontal wind speed are decomposed into a geostrophic and a residual part in this work:

$U=u+u^{\prime}$

$V=v+v^{\prime}$.

ARW was modified so that its dynamical core only operates on the residual wind field $\left(u^{\prime}, v^{\prime}, w^{\prime}\right)$, with the vertical wind speed $w^{\prime}$. The surface flux of horizontal momentum due to surface drag is calculated from $U_{\mathrm{l}=1}$ and $V_{\mathrm{l}=1}$, which creates shear in the vertical profiles of $u^{\prime}$ and $v^{\prime} . u^{\prime}$ and $v^{\prime}$ are nudged with Rayleigh damping towards 0 at the top of the model domain over a $250 \mathrm{~m}$ layer. Applying the ARW dynamical core to the residual wind field in this manner is akin to moving the model domain with the geostrophic wind, although its geographic location remains fixed. This approach facilitates the analysis of horizontal spatial structures such as closed and open cells, which remain stationary with respect to the domain. In the original implementation of ARW, the closed and open cells would be advected through the domain by the geostrophic wind.

\section{Simulations}

Simulations are conducted on a domain that is sufficiently large to allow statistical analysis of mesoscale organization, yet with a spatial and temporal resolution that enables the representation of individual cloud elements (cloud systemresolving simulations, Randall et al., 2003). The domain covers an area of $100 \times 100 \mathrm{~km}^{2}$ with a height of $1800 \mathrm{~m}$. The horizontal (vertical) resolution is $300 \mathrm{~m}(30 \mathrm{~m})$, respectively, the temporal resolution is $3 \mathrm{~s}$. Periodic lateral boundary conditions are used. The setup has been successfully used to simulate the transition from the closed- to the open-cell state
(Wang and Feingold, 2009a, b; Wang et al., 2010; Kazil et al., 2011), and has been shown to capture the essence of finer resolution simulations (Wang and Feingold, 2009a). The domain is located at $122^{\circ} \mathrm{W}, 31.5^{\circ} \mathrm{N}$, with a Coriolis parameter of $7.62 \times 10^{-5} \mathrm{~s}^{-1}$. A large-scale divergence of $3.75 \times 10^{-6} \mathrm{~s}^{-1}$ is assumed, which gives the large-scale subsidence at each level when multiplied by the altitude. The simulations are initialized on 11 July 2001 at 04:00:00 UT with idealized vertical profiles (Fig. 1) of potential temperature and total water (as water vapor mixing ratio). These profiles are based on measurements during the second Dynamics and Chemistry of Marine Stratocumulus (DYCOMS II) field campaign research flight 2 (RF02) on 11 July 2001 over the northeast Pacific (Stevens et al., 2003, 2005). They differ from the original DYCOMS II RF02 profiles by a $100 \mathrm{~m}$ deeper boundary layer to allow for a higher liquid water path, stronger cloud top cooling in the closed-cell state, and enhanced rain formation in the open-cell state. Small vertical and horizontal random variations are superposed on these initial profiles to set the boundary layer circulation in motion, for which a spin-up period of $3 \mathrm{~h}$ is allotted. Collisioncoalescence, sea salt emissions, and aerosol dry deposition are disabled for the duration of the spin-up period. The sea surface temperature is held constant at $292.5 \mathrm{~K}$, and a northwesterly geostrophic wind of $u=1 \mathrm{~m} \mathrm{~s}^{-1}$ and $v=-1 \mathrm{~m} \mathrm{~s}^{-1}$ is prescribed. An inert tracer is used to diagnose entrainment of free tropospheric air into the boundary layer. The inert tracer is initialized with the (arbitrary) number mixing ratio of $1 \mathrm{ppt}$ above the inversion and with $0 \mathrm{ppt}$ below. The idealized initial and boundary conditions chosen here produce, depending on the initial aerosol number concentration, a long-lived closed- or open-cell state. Results are sampled every $10 \mathrm{~min}$.

The simulations in this work (Table 1) have identical setups except for the initial aerosol particle number concentration and the way the surface heat and sea salt fluxes are determined. The surface fluxes are either calculated interactively or prescribed from another simulation. Prescribed surface fluxes are spatially homogenized, i.e., the domainaveraged flux, with a temporal resolution of $10 \mathrm{~min}$ used at every location of the domain. Initial aerosol number concentrations of 300 and $100 \mathrm{mg}^{-1}$ are used both in the free troposphere and the boundary layer, at a median particle diameter of $0.1 \mu \mathrm{m}$ and with a geometric standard deviation of 1.5. These initial aerosol concentrations lead, with interactive surface fluxes, to a closed- (simulation $\mathcal{S}_{\bullet}$ ) or open-cell (simulation $\mathcal{S}_{\circ}$ ) state, respectively.

\section{Results and discussion}

\subsection{The closed- and open-cell state}

Simulations $\mathcal{S}_{\bullet}$ and $\mathcal{S}_{\circ}$, which produce a closed- and an opencell state, respectively, are discussed here. Cloud optical 
Table 1. List of simulations. Closed and open circles represent the closed- and open-cell character of the simulations. The setup of the simulations is identical in all aspects other than those listed here. In simulations with prescribed surface fluxes, the fluxes are spatially homogenized.

\begin{tabular}{|c|c|c|c|c|c|c|}
\hline \multirow[t]{2}{*}{ Simulation } & \multicolumn{3}{|c|}{$\begin{array}{l}\text { initial aerosol concentration } \\
\qquad\left(\mathrm{mg}^{-1}\right)\end{array}$} & \multicolumn{3}{|c|}{ surface flux } \\
\hline & Aitken & accumulation & coarse & sensible heat & latent heat & sea salt \\
\hline $\mathcal{S}_{\bullet}$ & 0 & 300 & 0 & interactive & interactive & interactive \\
\hline $\mathcal{S}_{\circ}$ & 0 & 100 & 0 & interactive & interactive & interactive \\
\hline $\mathcal{S}_{\otimes}$ & 0 & 100 & 0 & $\mathcal{S}_{\bullet}$ & $\mathcal{S}_{\bullet}$ & $\mathcal{S}_{\bullet}$ \\
\hline $\mathcal{S}_{\circ}^{\prime}$ & 0 & 100 & 0 & interactive & interactive & 0 \\
\hline $\mathcal{S}_{0}^{\prime \prime}$ & 0 & 100 & 0 & $\mathcal{S}_{\circ}$ & $\mathcal{S}_{\bullet}$ & $\mathcal{S}_{\bullet}$ \\
\hline $\mathcal{S}_{\bar{\bullet}}$ & 0 & 300 & 0 & $\mathcal{S}_{\bullet}$ & $\mathcal{S}_{\bullet}$ & $\mathcal{S}_{\bullet}$ \\
\hline $\mathcal{S}_{\overline{0}}$ & 0 & 100 & 0 & $\mathcal{S}_{\circ}$ & $\mathcal{S}_{\circ}$ & $\mathcal{S}_{\circ}$ \\
\hline
\end{tabular}

depth after 12 and $36 \mathrm{~h}$ is given in Fig. 2. Simulation $\mathcal{S}_{\bullet}$ exhibits a closed-cell state with cell diameters up to $\approx 12 \mathrm{~km}$ after $12 \mathrm{~h}$ (Fig. $2 \mathrm{a}$ ). In the $24 \mathrm{~h}$ that follow, the closed-cell state also develops mesoscale organization on a scale of approximately $50 \mathrm{~km}$ (Fig. 2b), indicating the emergence of a corresponding boundary layer circulation. This mesoscale organization hints at a richness in the dynamical structure of closed stratocumulus decks that lends itself to future investigation, but shall not be the subject of this work. Simulation $\mathcal{S}_{\text {。 pro- }}$ duces open cells that measure typically $20 \mathrm{~km}$ in diameter after $12 \mathrm{~h}$ (Fig. $2 \mathrm{c}$ ). The optical depth reaches maximum values of $\approx 80$ in the well-defined cell walls. In the cell centers, optical depth ranges from 0 to occasional maximum values of up to 15 . The elevated optical depth inside the open cells likely arises from the absence of short-wave radiation in the simulation, which would otherwise lead to evaporation of cloud water and to lower optical depths. The open cells maintain their size over the $24 \mathrm{~h}$ that follow (Fig. 2d) but their walls become broken and less well-defined. The optical depth in many cell centers is now reduced to values $<0.5$ (Fig. $2 \mathrm{~d}$ ).

Figure 3 shows time series of selected quantities in simulation $\mathcal{S}_{\bullet}$ and $\mathcal{S}_{\circ}$. Cloud fraction remains near unity in the closed-cell state of $\mathcal{S}_{\bullet}$, but declines continuously in the opencell state of $\mathcal{S}_{\circ}$ (Fig. 3a), in accord with the progression in open-cell structure from 12 to $36 \mathrm{~h}$ seen in Fig. 2 (break-up of cell walls, reduced optical depth in the cell centers). Liquid water path (Fig. 3b) drops rapidly in both simulations once collision-coalescence has been enabled (at $3 \mathrm{~h}$ into the simulations), as the ensuing rain transports liquid water from the cloud into the sub-cloud layer. There, most of the rain evaporates, as is evident from the absence of surface rain in $\mathcal{S}$. and from the very low surface rain early in $\mathcal{S}_{\circ}$ (Fig. 3c). The initial decline in liquid water path is steeper in $\mathcal{S}_{\circ}$ compared to $\mathcal{S}_{\bullet}$ because of its lower initial aerosol concentration (Table 1), which accelerates collision-coalescence and rain formation. After the initial reduction, the liquid water path exhibits a periodic variation in $\mathcal{S}_{\text {。 }}$ (Fig. 3b). A similar oscillation, with a later onset, emerges in the surface rain time series of $\mathcal{S}_{\circ}$ (Fig. 3c). The oscillations in open-cell surface rain
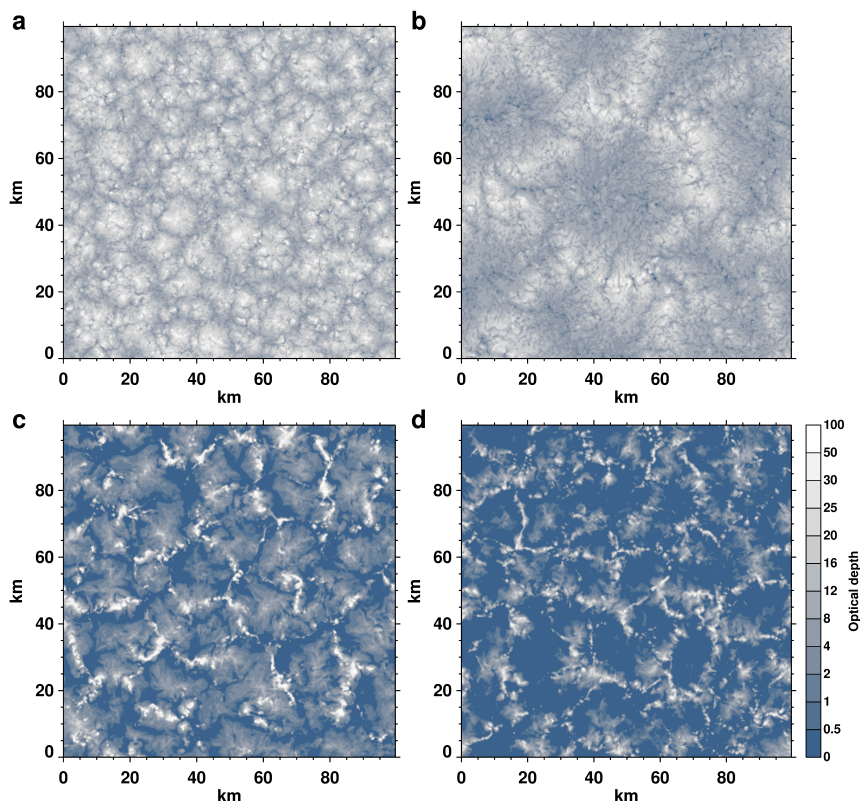

Fig. 2. Cloud optical depth in simulation $\mathcal{S}_{\bullet}(\mathbf{a}, \mathbf{b})$ and $\mathcal{S}_{\circ}(\mathbf{c}, \mathbf{d})$, after $12 \mathrm{~h}(\mathbf{a}, \mathbf{c})$ and $36 \mathrm{~h}(\mathbf{b}, \mathbf{d})$.

were first described by Feingold et al. (2010) and shown to be a consequence of the spatial organization and rearrangement of the synchronized open-cell state.

The surface sensible and latent heat fluxes in simulation $\mathcal{S}_{\text {. }}$ and $\mathcal{S}_{\circ}$ are examined in Fig. $3 \mathrm{~d}$ and e. The open-cell $\left(\mathcal{S}_{\circ}\right)$ sensible heat flux undergoes an initial boost followed by a slow gradual lapse (Fig. 3d); the closed-cell $\left(\mathcal{S}_{\bullet}\right)$ sensible heat flux experiences an initial, more rapid reduction before settling into an asymptotic decline. The open-cell sensible heat flux exceeds its closed-cell counterpart by approximately a factor of 3 for most of the duration of the simulations. The open-cell latent heat flux jumps briefly at the outset, and then undergoes a nearly linear decline thereafter, while the closed-cell state latent heat flux remains nearly constant (Fig. 3e). 
a
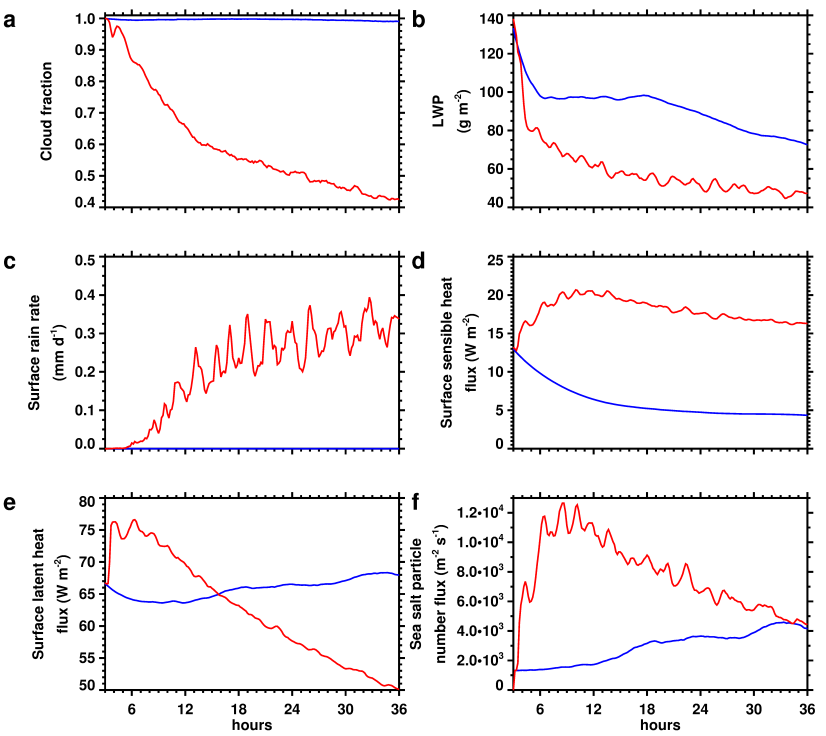

Fig. 3. Domain-averaged time series of selected quantities in simulation $\mathcal{S}_{\bullet}$ (blue) and $\mathcal{S}_{\circ}$ (red).

The open-cell surface heat fluxes exhibit oscillations reminiscent of those in liquid water path (Fig. 3b), as does the open-cell surface sea salt flux (Fig. 3f). The open-cell sea salt aerosol flux from the surface is also strongly enhanced (by up to a factor of 8) relative to the closed-cell state (Fig. 3f). This enhancement is transient, and the sea salt flux assumes almost identical values at the end of the simulations (after $36 \mathrm{~h}$ ). Sea salt emissions are parameterized in the simulations as a function of the surface wind speed only, and the sea salt flux enhancement and oscillations reflect variations in the open-cell surface wind speed.

Figure 4 examines the causes for the temporal evolution of the surface heat fluxes in simulation $\mathcal{S}_{\bullet}$ and $\mathcal{S}_{\circ}$. The analysis is based on Eq. (1). In $\mathcal{S}_{\boldsymbol{\bullet}}$, the temporal evolution of the surface sensible heat flux is driven by air temperature rather than by surface wind speed - the surface layer warms over the course of the simulation, leading to a decrease in sensible heat flux, which is not compensated for by the concurrent increase in surface total horizontal wind speed (Fig. 4a). The limited influence of surface wind speed is confirmed by the absence of its hour-scale variability in the sensible heat flux time series. In contrast, the hour-scale surface wind speed variability appears in the surface latent heat flux (Fig. 4b). This underscores the role of surface wind speed for latent heat flux in the closed-cell state, which contributes to its increase over the course of $\mathcal{S}_{\text {. }}$.

In the open-cell state $\left(\mathcal{S}_{\circ}\right)$, surface total horizontal wind speed and surface air temperature act conjointly on the simulation timescale in enhancing or suppressing the surface sensible heat flux (Fig. 4c): temperature is reduced when wind speed is enhanced and vice versa, resulting in a corresponding increase or decrease of sensible heat flux, respectively.
This behavior also appears on shorter (hourly) timescales: the temporal anomaly of the wind speed, temperature, and sensible heat flux time series (Fig. 4e) reveals a tightly correlated, periodic behavior of these quantities in which wind speed and temperature act in accord to increase or decrease the sensible heat flux. The unlagged periodicity of the time series indicates an underlying mechanism that drives both surface wind speed and air temperature and thereby the surface sensible heat flux.

The surface latent heat flux in $\mathcal{S}_{\circ}$ declines on the simulation timescale by conjoint action of surface wind speed and water vapor (Fig. 4d): the temporal evolution of the wind speed is characterized by a general decline over the duration of the simulation, while water vapor has the opposite trend. On shorter (hourly) timescales (Fig. 4f), the tightly correlated periodic behavior, seen in the sensible heat flux (Fig. 4e), reappears. However, unlike in the case of sensible heat flux, where wind speed and temperature oscillations act in unison, the determinant quantities of latent heat flux, wind speed and water vapor, oscillate in discord: peaks in wind speed, which enhance the latent heat flux, coincide with peaks in water vapor, which suppress the latent heat flux. The unlagged periodicity of the time series indicates an underlying mechanism that drives both surface wind speed and water vapor and thereby the surface latent heat flux. The mechanism responsible for the oscillations in the surface sensible and latent heat flux and in the sea salt flux, as well as in their determinant quantities, will be the focus of the next section.

Fig. 5 shows the inversion height time series in simulation $\mathcal{S}_{\bullet}$ and $\mathcal{S}_{\mathrm{o}}$. The inversion heights diverge early in the simulations, at $1060 \mathrm{~m}$, after which the closed-cell state boundary layer $\left(\mathcal{S}_{\bullet}\right)$ grows on average by $1.8 \mathrm{~mm} \mathrm{~s}^{-1}$, while its opencell counterpart $\left(\mathcal{S}_{\circ}\right)$ recedes on average by $1.65 \mathrm{~mm} \mathrm{~s}^{-1}$. When large-scale subsidence is accounted for, the boundary layer entrains free tropospheric air in both simulations, however, on average at a higher rate in $\mathcal{S}_{\bullet}$ and at a lower rate in $\mathcal{S}_{\circ}$.

\subsection{Imprint of open-cell oscillations on boundary layer base properties}

The tightly correlated oscillations in the open-cell $\left(\mathcal{S}_{\circ}\right)$ surface heat fluxes and their determinant quantities surface wind speed, temperature, and water vapor (Fig. $4 \mathrm{c}-\mathrm{f}$ ) indicate a common underlying mechanism. It will be shown that this mechanism is the dynamics of the open-cell state (Feingold et al., 2010), in which the periodic formation of updrafts, which occurs when surface outflows from a preceding open cell generation converge, leads to the formation of clouds, rain, downdrafts, cold and moist pools, and surface wind divergence. These drive surface air temperature and water vapor, and eventually surface heat fluxes. Domain-wide oscillations of dynamics, cloud properties, and surface rain will be identified, and their causal relationship to the oscillations in 
a

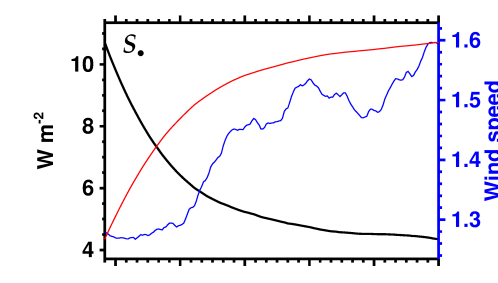

C

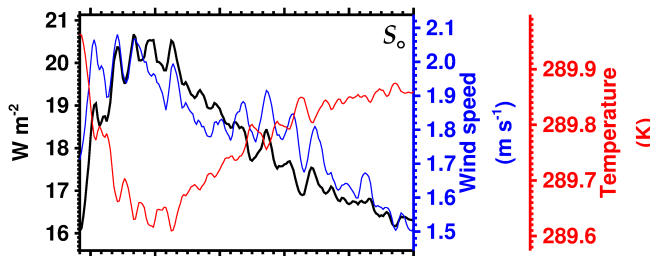

b

e

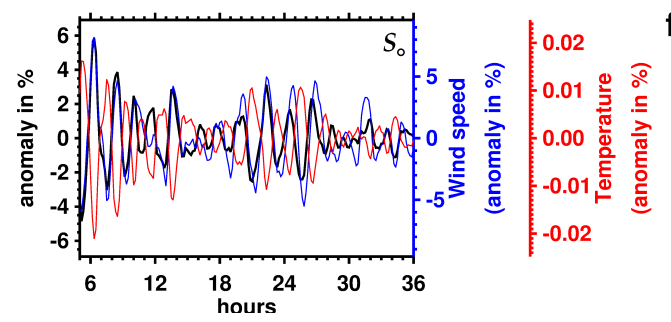

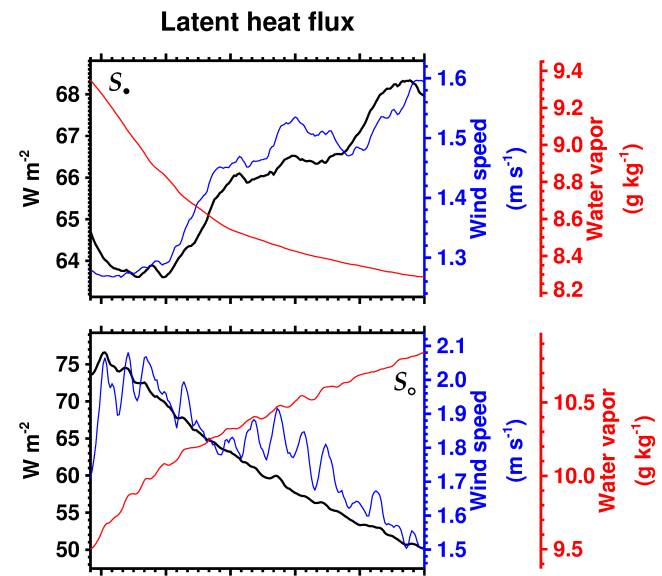

d

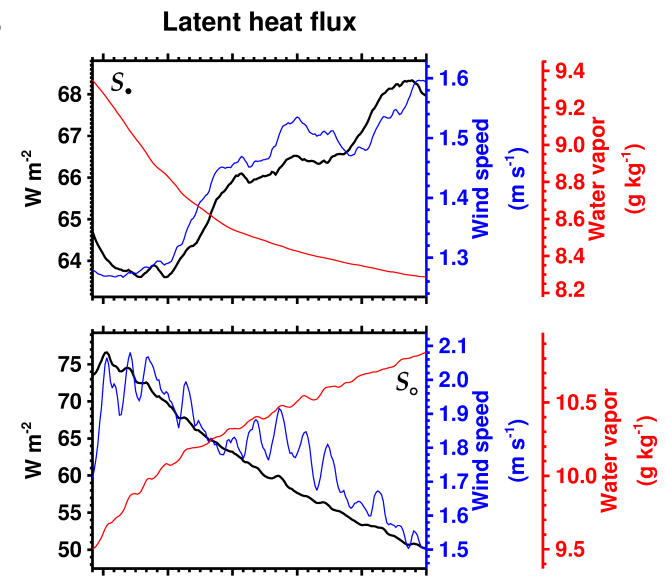

f

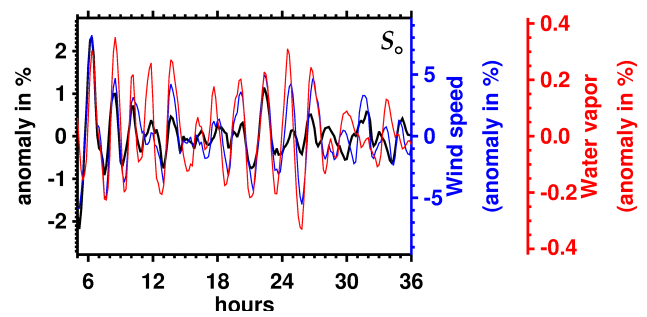

Fig. 4. Domain-averaged surface sensible and latent heat fluxes for the simulation $\mathcal{S}_{\bullet}(\mathbf{a}, \mathbf{b})$ and $\mathcal{S}_{\circ}(\mathbf{c}, \mathbf{d})$, plotted with their determinant quantities (domain-averaged surface total horizontal wind speed, surface air temperature, and surface water vapor). Panels (e) and (f) show the temporal anomalies (against a $3 \mathrm{~h}$ running mean) of the $\mathcal{S}_{\circ}$ data $(\mathbf{c}, \mathbf{d})$.

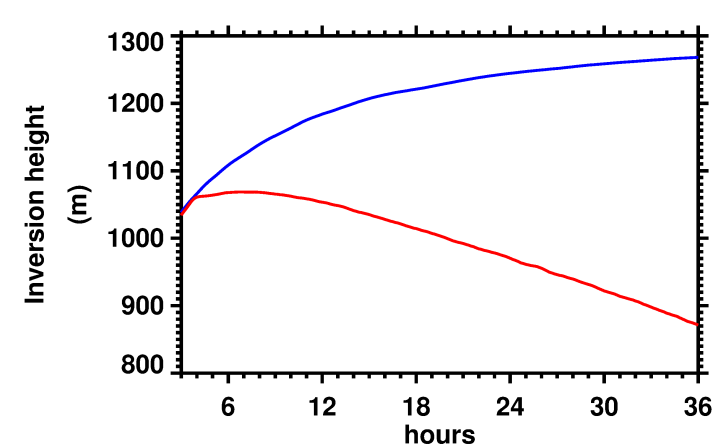

Fig. 5. Domain-averaged inversion height time series in simulation $\mathcal{S}_{\bullet}$ (blue) and $\mathcal{S}_{\circ}$ (red).

surface wind speed, surface air temperature and water vapor, and ultimately to the surface heat fluxes demonstrated.

Figure 6 shows the time series of latent heat release (heating of the air from condensation of water vapor), liquid water path, and surface rain, and their temporal anomalies in simulation $\mathcal{S}_{\text {o }}$. Latent heat release is used to diagnose cloudforming dynamics: as water vapor condenses in updrafts, latent heat is released. The three time series exhibit oscillations with a mean period of $\approx 2 \mathrm{~h}$ (Fig. 6a). The temporal anomalies of the time series (Fig. 6b) reveal delays that reflect their causal relationships: latent heat release, indicating cloud-forming updrafts, leads the oscillations, followed by liquid water path, which builds up in the updrafts. The grow- ing liquid water path renders rain formation by collisioncoalescence more efficient, and some of the resulting rain arrives, with delay, at the surface. The oscillations in latent heat release, liquid water path, and surface rain reflect the presence of open-cell dynamics throughout the simulation $\mathcal{S}_{\circ}$. The delays are discussed in Sect. 4.3.2.

Figure 7 shows the temporal anomaly of surface rain, plotted with the anomaly of surface air temperature, water vapor, and total horizontal wind speed. The time series exhibit a periodic pattern that constitutes an extension of the oscillations seen in Fig. 6. Here, surface rain peaks are followed by dips in surface air temperature, jumps in surface water vapor, and increases in surface wind speed. The causality of this sequence can be explained with downdrafts, which, cooled by evaporation of rain water, form surface cold pools associated with surface wind divergence (Jensen et al., 2000; Comstock et al., 2005; Stevens et al., 2005; Comstock et al., 2007; Wood et al., 2011). The applicability of this paradigm will be demonstrated by analysis of the spatial distribution of the quantities involved.

For reference in the following discussion, the surface rain rate at a given time for simulation $\mathcal{S}_{\circ}$ is shown in Fig. 8, along with the residual horizontal surface wind field. The connection of surface rain and surface wind divergence is evident, as the residual surface wind originates from rain locations (Fig. 8). However, surface divergence also occurs at locations without surface rain, where rain in the associated downdraft 

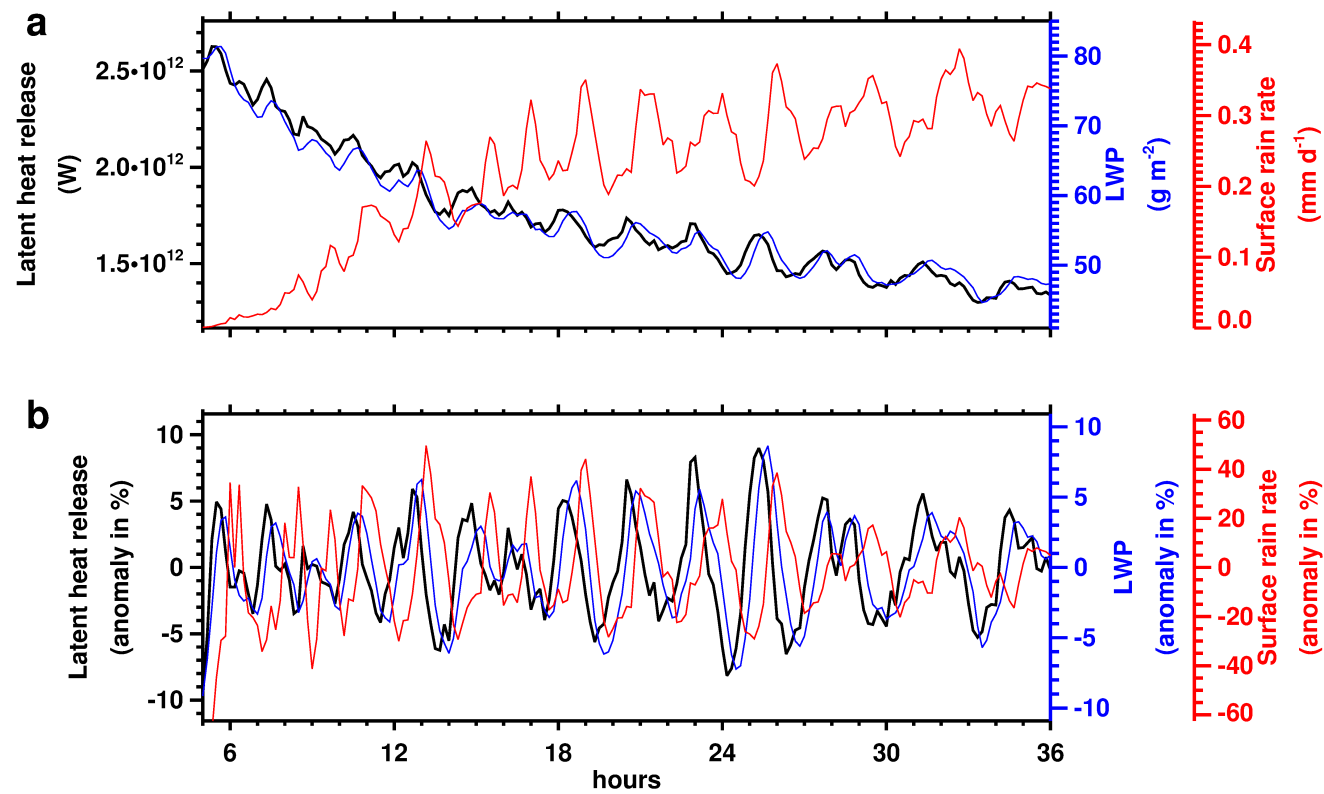

Fig. 6. (a) domain-integrated latent heat release (heating of the air from condensation of water vapor), domain-averaged liquid water path and surface rain, and (b) their temporal anomalies (against a $3 \mathrm{~h}$ running mean) in simulation $\mathcal{S}_{\mathrm{o}}$.
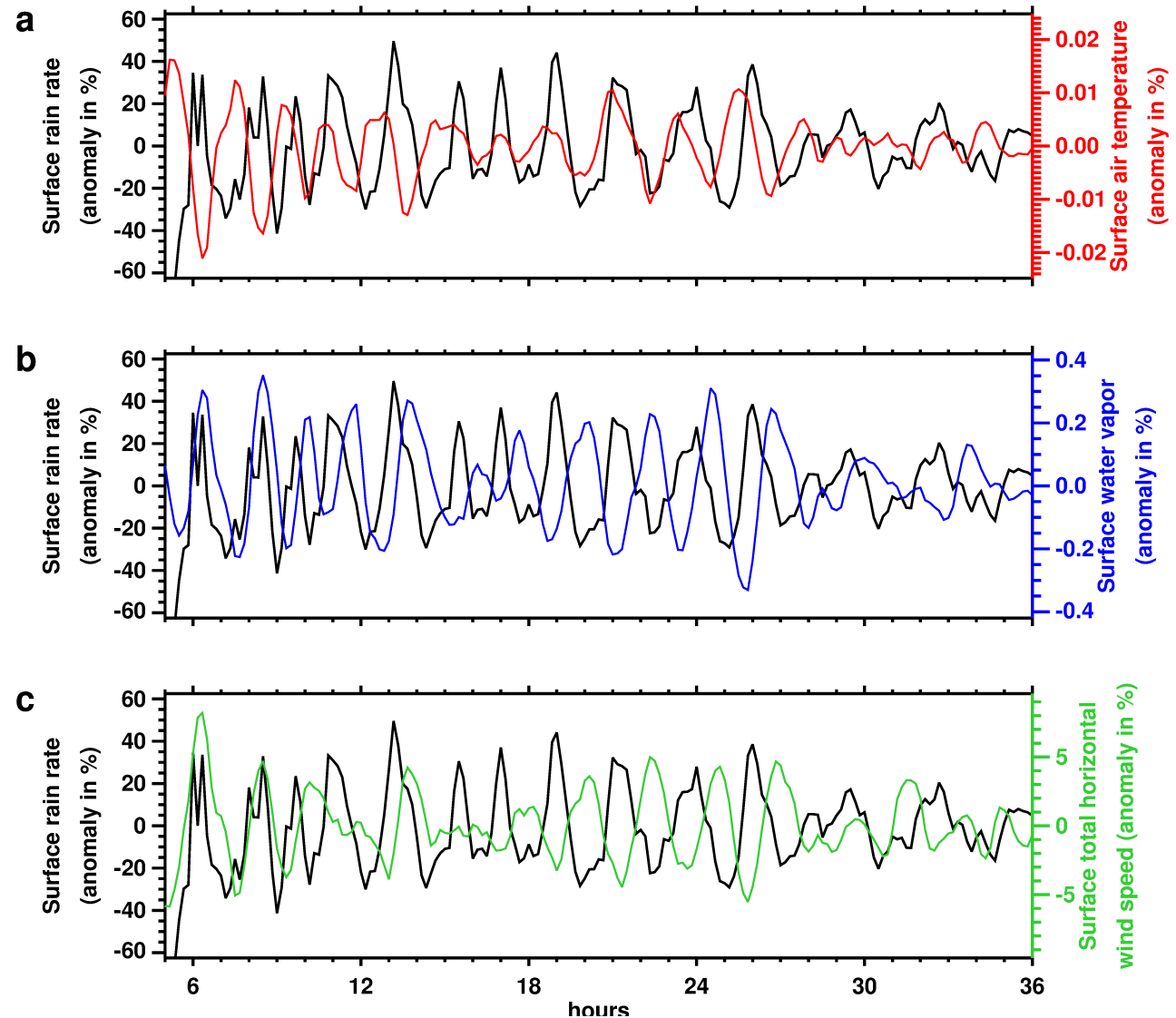

Fig. 7. Temporal anomalies (against a $3 \mathrm{~h}$ running mean) of surface rain and (a) surface air temperature, (b) water vapor, and (c) total horizontal wind speed in simulation $\mathcal{S}_{\circ}$. 


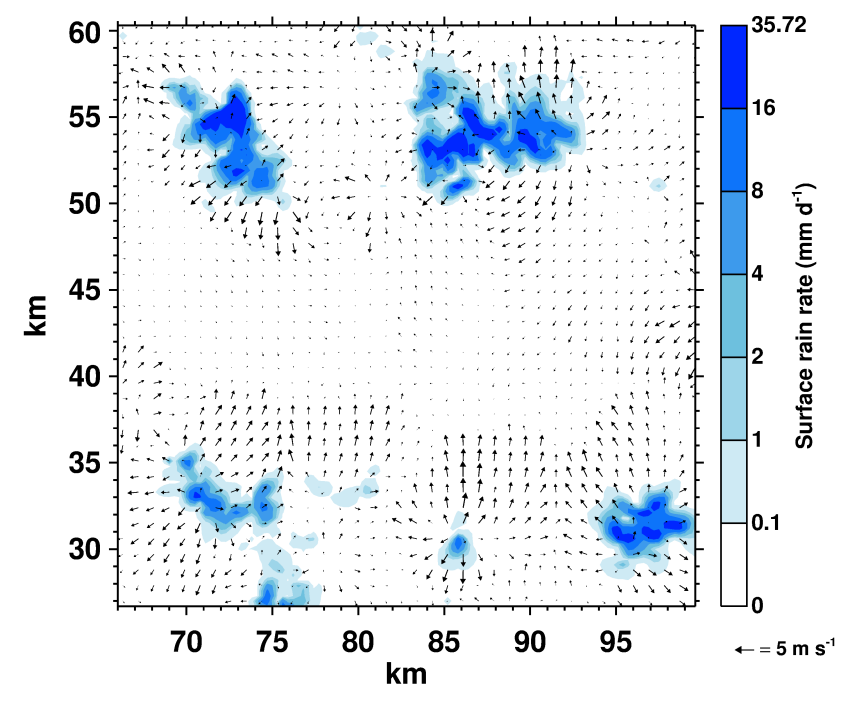

Fig. 8. Surface rain rate and residual horizontal surface wind field after $26 \mathrm{~h}$ in a select region of simulation $\mathcal{S}_{\mathrm{O}}$. The color scale extends to the rain rate maximum.

has evaporated before reaching the surface, or where surface rain has ceased.

Figure 9 shows the spatial distribution of the surface rain rate with surface air temperature (a) and water vapor (b) at a given time for simulation $\mathcal{S}_{\circ}$. Surface air temperature is reduced at surface rain locations (Fig. 9a), in agreement with the paradigm of evaporatively cooled downdrafts forming cold pools. The association of surface rain and cold pools in Fig. 9a is evident despite the unremarkable correlation coefficient between the surface rain rate and surface air temperature of -0.37 . Applying a circular low-pass filter with a diameter of $4500 \mathrm{~m}$ to the data improves the correlation coefficient to -0.59 (Supplement, Fig. A-1a). Collocation of surface rain and cold pools was found previously in opencell simulations by Berner et al. (2011). However, surface rain and surface water vapor exhibit a low correlation coefficient of 0.21 (Fig. 9b), which improves by low-pass filtering to only 0.38 (Supplement, Fig. A-1b). It will be shown in the following that despite this low spatial correlation, water vapor is elevated in the cold pools.

Figure 9 shows surface air temperature (c) and water vapor (d) with the residual horizontal surface wind field at a given time for simulation $\mathcal{S}_{0}$. Surface air temperature is depressed and water vapor elevated around locations of surface divergence. Temperature and water vapor are well-correlated with residual horizontal surface wind speed, with correlation coefficients of -0.64 ( -0.72 after filtering) and $0.6(0.72$ after filtering), respectively: surface air temperature is low and water vapor high at locations of high residual horizontal surface wind speed. Visual inspection of Fig. 8 confirms that the residual wind speed diverges and is highest around rain locations. Precipitating downdrafts hence depress surface air temperature and raise surface water vapor, and form cold pools with elevated humidity, despite the low correlation of surface rain and surface water vapor.

We hypothesize that the radial distribution of surface air temperature and water vapor in the cold pools and its extension around the cold pools (Fig. 9c,d) is responsible for the fact that surface air temperature correlates better than surface water vapor with surface rain: temperature is lowest in the center of the cold pools, increases with distance from their centers, and is highest outside the cold pools (Fig. 9c). In contrast, water vapor is generally not, as one might expect, highest in the cold pool centers, where surface rain is strongest, but in water vapor "halos" along their periphery, where the cold pool outflows are strongest (see, e.g., the cold pool located at $88 \mathrm{~km}$ west-east and $32 \mathrm{~km}$ south-north in Fig. 9d). Outside cold pools, water vapor is depressed. It can be argued that the radial variation of surface air temperature and water vapor inside the cold pools is due to the action of the surface sensible and latent heat fluxes (Fig. 9e, f), which, driven by the divergent surface wind field in the cold pools, heat and humidify the air. Consequently, the air that has traveled farthest from the cold pool centers would be warmest and most humid.

\subsection{Imprint of spatial organization on boundary layer base properties}

The imprint of the closed- and open-cell state dynamical and cloud structure on the spatial distribution of boundary layer base properties is discussed here. The spatial structure of the closed-cell state will be shown to determine the surface distribution of surface air temperature and water vapor by entrainment of dry free tropospheric air, and, to a lesser degree, the surface sensible and latent heat fluxes. Open-cell cloud formation, optical depth, and cloud water path, followed by rain water path will be established as predictors of the spatial distribution of surface air temperature and surface sensible heat flux, but not of surface water vapor nor surface latent heat flux.

\subsubsection{Closed-cell state}

Figure 10a shows cloud optical depth and the surface mixing ratio of an inert tracer in the closed-cell state at a given time in simulation $\mathcal{S}_{\bullet}$ (see Fig. 2a for an unobstructed view of the cloud structure). The inert tracer mixing ratio was initialized with $1 \mathrm{ppt}$ in the free troposphere and with zero in the boundary layer. As the inversion rises in $\mathcal{S}_{\bullet}$ (Fig. 5), the inert tracer is entrained with free tropospheric air into the boundary layer. Visual inspection of Fig. 10a reveals elevated inert tracer surface mixing ratios at locations where cloud optical depth is low. Reduced cloud optical depth is associated with downdrafts in the closed-cell state. Conversely, inert tracer surface mixing ratios are depressed at locations of high cloud optical depth, which are associated with updrafts. The spatial correlation coefficient of cloud optical depth and the inert 
a

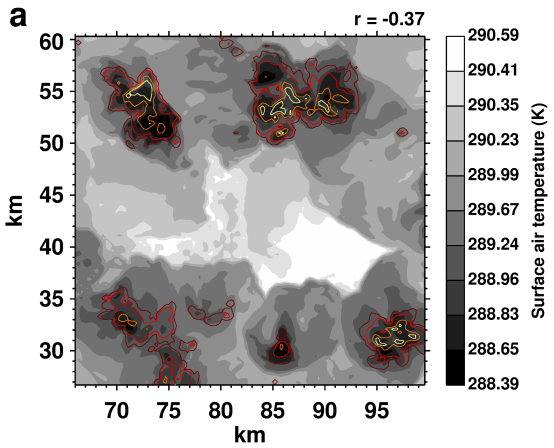

C
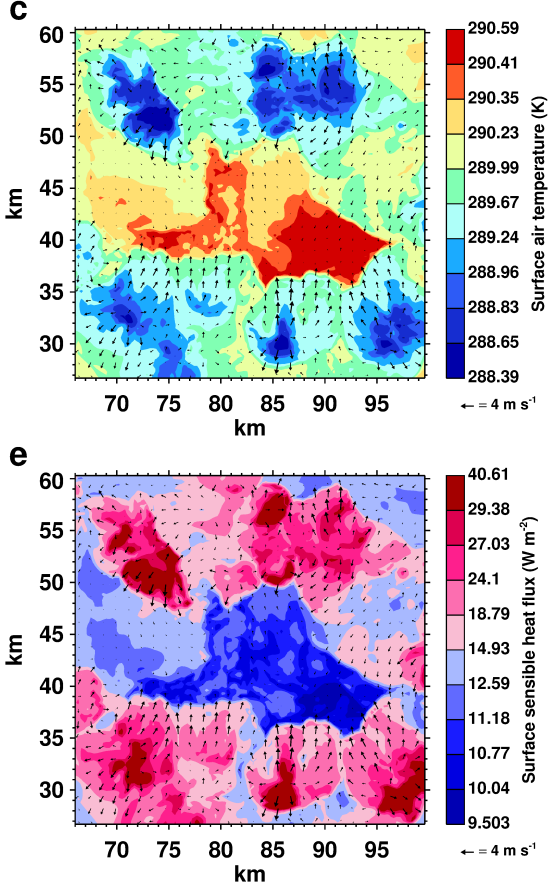

b
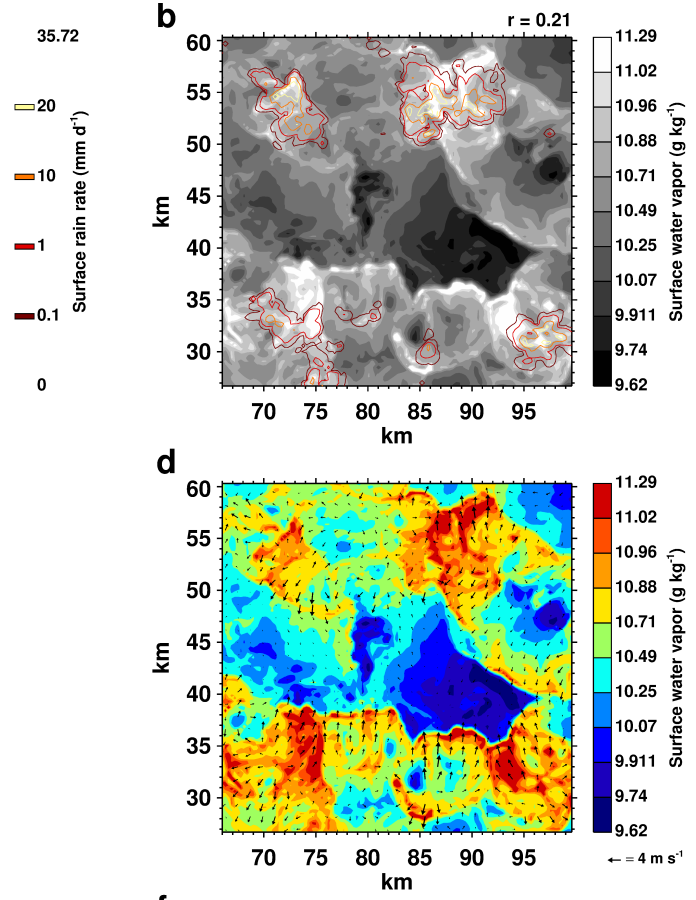

f

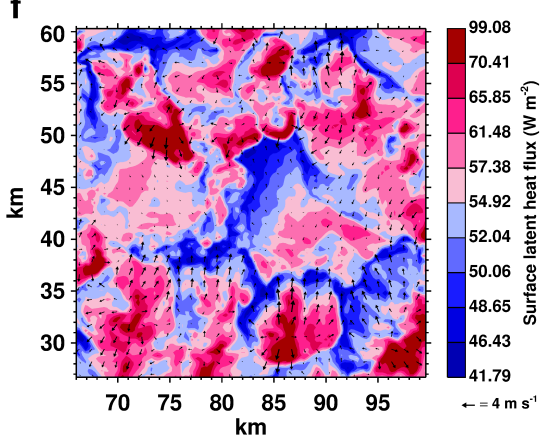

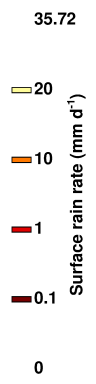

.72

Fig. 9. Surface air temperature (a) and water vapor (b) superimposed with the surface rain rate; surface air temperature (c) and water vapor (d) with the residual horizontal surface wind field; and the surface sensible (e) and latent (f) heat flux with the residual horizontal surface wind field, after $26 \mathrm{~h}$ in a select region of simulation $\mathcal{S}_{\circ}$. Domain-wide correlation coefficients are given for pairs of scalar quantities. Irregular contour intervals (at select percentiles of the data) are used for better visualization. Color scales are bounded by minima and maxima of the data. Minimum and maximum line contours are suppressed. The corresponding spatially filtered data are shown in the Supplement, Fig. A-1.

tracer surface mixing ratio of -0.34 at the time in question (Fig. 10a), although not particularly high, reflects this association; the correlation coefficient improves to -0.51 after filtering (Supplement, Fig. A-2a). The imprint of the closedcell state dynamics on the boundary layer base is also illustrated in Fig. 10b, which shows the surface distribution of the inert tracer together with the residual horizontal surface wind field. The inert tracer is more abundant at locations of surface divergence, which, owing to mass continuity, are locations of downdrafts. The association of inert tracer concentration and surface divergence is brought out clearly by applying a spatial filter (Supplement, Fig. A-2b).

The surface distribution of the inert tracer is highly correlated with the distribution of surface air temperature $(r=$ 0.93 , Fig. 10c) and water vapor mixing ratio $(r=-0.94$
Fig. 10d): surface air temperature is enhanced (depressed) and water vapor depressed (enhanced) at locations of high (low) inert tracer mixing ratios, respectively. The high correlations are expected in the well-mixed boundary layer in simulation $\mathcal{S}_{\bullet}$, in which entrainment of dry free tropospheric air, by reducing the water content of descending air parcels and thereby latent heat uptake by evaporation during their descent, leads to drier and warmer air at the surface. This is hence the mechanism by which the horizontal spatial structure of the closed-cell state imprints itself onto surface air temperature and water vapor.

The spatial structure of the closed-cell state also emerges in the surface heat fluxes, as they respond to surface air temperature and water vapor (Eq. 1). The surface sensible heat flux is reduced at locations with higher inert tracer levels 
a
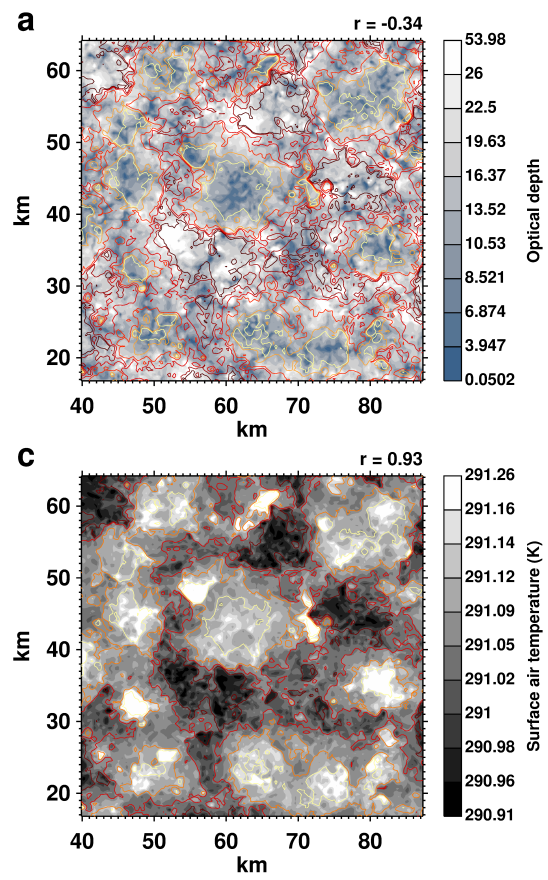

e

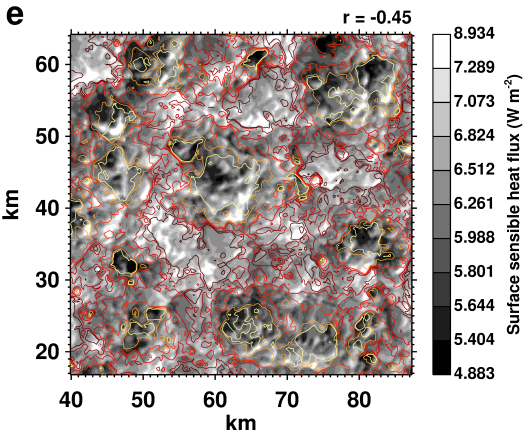

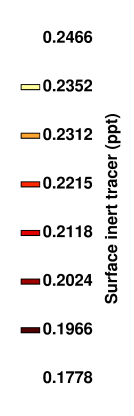

b

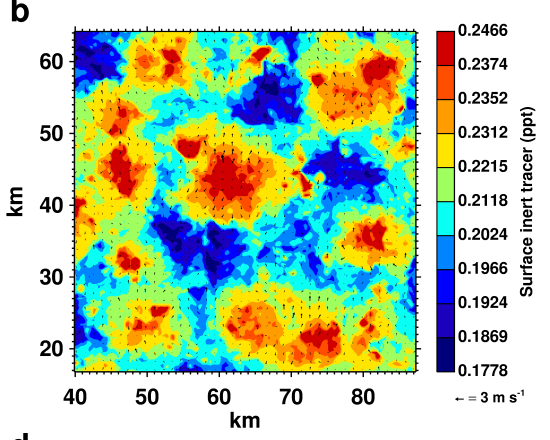

d
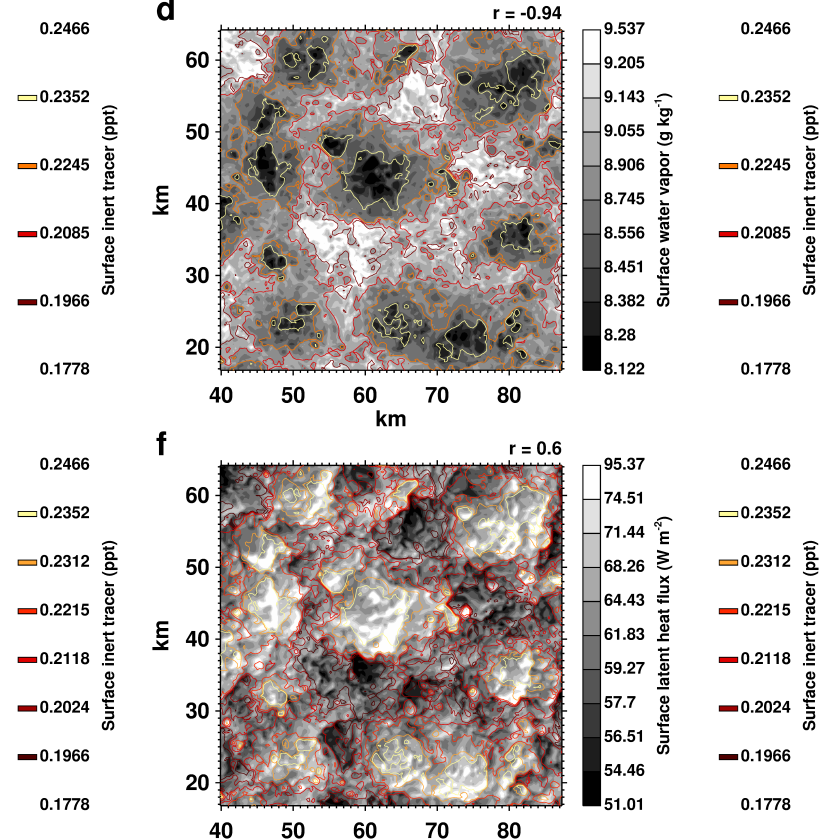

f

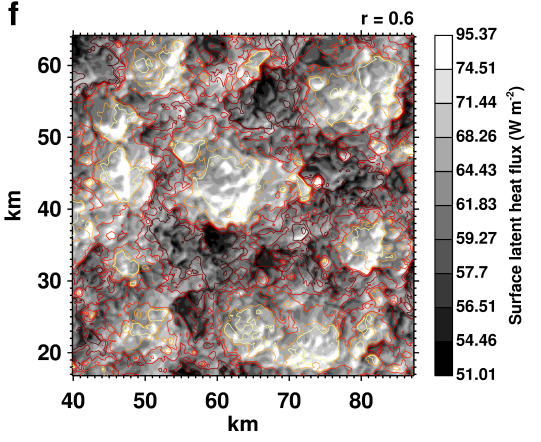

0.2466

$\square 0.2352$

$\square 0.2312$ 흥

0.2215

$=0.2118 \stackrel{\text { : }}{\stackrel{5}{ \pm}}$

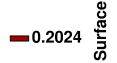

$=0.1966$

0.1778

Fig. 10. Surface mixing ratio of the inert tracer, with (a) cloud optical depth, (b) residual horizontal surface wind field, (c) surface air temperature, (d) surface water vapor, and surface sensible (e) and latent (f) heat flux, after $12 \mathrm{~h}$ in a select region of simulation $\mathcal{S}_{\mathbf{0}}$. Domainwide correlation coefficients are given for pairs of scalar quantities. Irregular contour intervals (at select percentiles of the data) are used for better visualization. Color scales are bounded by minima and maxima of the data. Minimum and maximum line contours are suppressed. The corresponding spatially filtered data are shown in the Supplement, Fig. A-2.

(Fig. 10e), where downdrafts supply warmer and drier air. Conversely, the latent heat flux is enhanced at these downdraft locations (Fig. 10f). Spatial filtering renders the connection clearly apparent (Supplement, Fig. A-2e, f). The correlation coefficients of the surface sensible and latent heat flux with the inert tracer are, however, only $r=-0.45$ (Fig. 10e) and $r=-0.6$ (Fig. 10f), respectively, lower than the correlation coefficients between the inert tracer and surface air temperature $(r=0.93$, Fig. 10c) and water vapor $(r=-0.94$, Fig. 10d). In other words, entrainment of dry free tropospheric air determines surface air temperature and water vapor to a greater degree than it determines surface heat fluxes. This is because the surface heat fluxes not only vary with surface air temperature and water vapor, but also with the total surface wind speed (Eq. 1): the total surface wind speed correlates well with the sensible and latent heat flux at $r=0.73$ and $r=0.82$, respectively, in simulation $\mathcal{S}_{\bullet}$ (for the time shown in Fig. 10). In conclusion, the closed-cell circulation imposes its horizontal spatial structure on boundary layer base properties such as surface air temperature and water vapor by entrainment of dry free tropospheric air, and, to a lesser degree, on the surface sensible and latent heat fluxes.

\subsubsection{Open-cell state}

Lagged spatial correlations between quantities in the opencell state $\left(\mathcal{S}_{\circ}\right)$ are analyzed in this section. An extremum in the lagged spatial correlation coefficient is interpreted as the manifestation of a causal relationship in which the spatial distribution of one quantity determines the spatial distribution of the other, after a delay or lag. The focus is on the open-cell state $\left(\mathcal{S}_{\circ}\right)$, where such lags materialize. In the more 
a

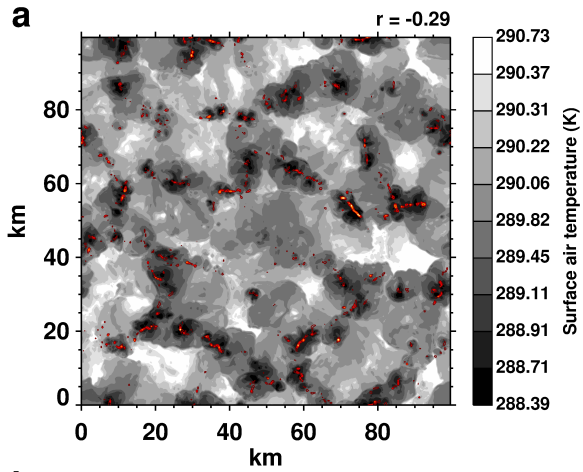

b

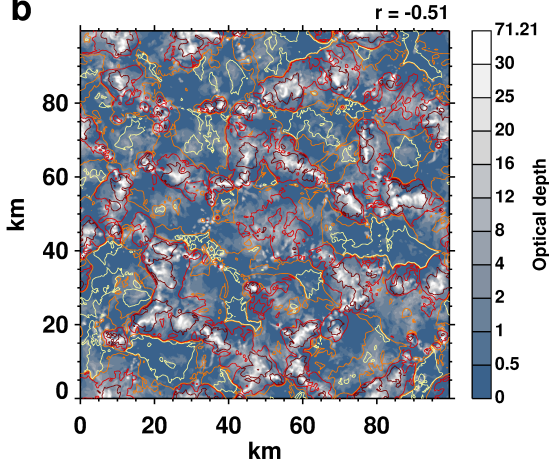

c

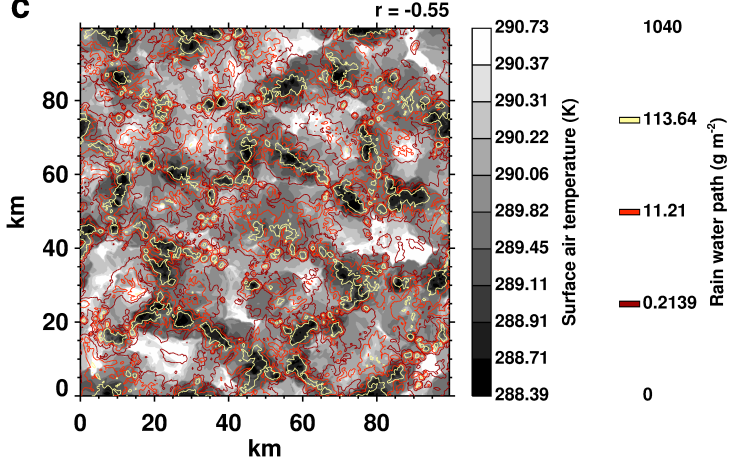

Fig. 11. Latent heat release path (a), cloud optical depth (b), and rain water path (c) with surface air temperature in simulation $\mathcal{S}_{\circ}$. Surface air temperature is shown after $26 \mathrm{~h}$, the latent heat release path $40 \mathrm{~min}$, cloud optical depth $30 \mathrm{~min}$, and rain water path $20 \mathrm{~min}$ earlier. Correlation coefficients of the data at these lags are given. Irregular contour intervals (at select percentiles of the data) are used for better visualization. Color scales are bounded by minima and maxima of the data. Minimum and maximum line contours are suppressed. The corresponding spatially filtered data are shown in the Supplement, Fig. A-3.

stationary (Feingold et al., 2010; Koren and Feingold, 2013) closed-cell state $\left(\mathcal{S}_{\bullet}\right)$, spatial correlations between quantities vary slowly with lag time, and peaks occur at a zero lag. Visual examples of lagged spatial correlations in simulation $\mathcal{S}_{\circ}$ are given in Fig. 11 (Supplement, Fig. A-3, after filtering). Tables 2 and 3 provide spatial correlation coefficients of selected quantities at lags of 0-60 min, at two different times in $\mathcal{S}_{\circ}$.
To facilitate the subsequent discussion, the role of opencell dynamics for surface air temperature, water vapor, and surface heat fluxes in the open-cell state is revisited. The residual wind speed correlates better (Table 2a) with surface air temperature and water vapor than the total wind speed (Table 2b). This underscores the role of the open-cell circulation in determining the spatial distribution of surface quantities. The underlying mechanism is the formation of moist cold pools and of surface divergence by precipitating downdrafts (Sect. 4.2). A consequence is a good correlation of the residual wind speed with the surface sensible heat flux, although not with the latent heat flux (Table 2a). The different behavior of surface sensible and latent heat flux arises from the synergetic action of increased surface wind speed and reduced temperature in the cold pools in driving the surface sensible heat flux, while the elevated surface wind speed and enhanced water vapor in the cold pools counteract each other in driving the surface latent heat flux (Sect. 4.1). Hence, the residual open-cell circulation drives surface air temperature, water vapor, the surface sensible heat flux, but to a lesser degree the surface latent heat flux. In the following it will be shown that cloud formation, cloud optical depth and liquid water path, and cloud and rain water path are good predictors of the spatial distribution of surface air temperature and sensible heat flux in the open-cell state, but not of surface water vapor and surface latent heat flux.

The spatial distribution of latent heat release path (vertical integral), which diagnoses cloud-forming updrafts, is shown with the lagged spatial distribution of surface air temperature in Fig. 11a (Supplement, Fig. A-3a after filtering). Latent heat release occurs at locations of future cold pools and areas of elevated surface sensible heat flux (not shown). The spatial correlation coefficients of latent heat release path and surface air temperature (and surface sensible heat flux) reach extrema at a lag of $\approx 40 \mathrm{~min}$ (Table 3a). Cloud formation hence predicts the distribution of surface air temperature and sensible heat flux. Cloud formation is, however, not a good predictor of surface water vapor and surface latent heat flux, with comparably low lagged correlation coefficients (Table 3a). We propose that this is due to the aforementioned discordant action of surface wind speed and enhanced water vapor in driving the cold pool surface latent heat flux (Sect. 4.1), and the formation of cold pool water vapor halos (Sect. 4.2).

Figure 11b (Supplement, Fig. A-3b after filtering) shows the spatial distribution of cloud optical depth with the lagged spatial distribution of surface air temperature. The spatial correlation coefficients of cloud optical depth and surface air temperature (and surface sensible heat flux) reach extrema at a lag of 20-30 min (Table 3b). Cloud optical depth hence becomes a predictor of surface air temperature and surface sensible heat flux approximately $10 \mathrm{~min}$ after cloud formation. Liquid water path is a similarly good predictor of the spatial distribution of surface air temperature and surface sensible heat flux (Table 3c), with a lag close to that of cloud optical depth (Table $3 \mathrm{~b}$ ). The lagged spatial correlation of cloud 
Table 2. Lagged spatial correlation coefficients of surface quantities in simulation $\mathcal{S}_{\circ}$. Correlation coefficients with an absolute value $\geq 0.66$ are highlighted in bold. Correlation coefficients in parentheses were calculated from data after filtering with a circular low-pass filter with a diameter of $4500 \mathrm{~m}$. Autocorrelation coefficients for lags $<0$ were not calculated. Correlation coefficients between the surface heat fluxes and surface wind speeds were not computed for lags $<0$, because surface heat fluxes are calculated from the simultaneous (total) wind speed at the lowest model level.

\begin{tabular}{|c|c|c|c|c|c|c|c|c|c|c|}
\hline & & \multirow[b]{2}{*}{$\begin{array}{l}\text { Time } \\
(\mathrm{min})\end{array}$} & \multicolumn{4}{|c|}{$t=11$ July 2001 21:00:00 UT } & \multicolumn{4}{|c|}{$t=12$ July $200106: 00: 00 \mathrm{UT}$} \\
\hline & & & Temperature & Water vapor & $\begin{array}{l}\text { Sensible } \\
\text { heat flux }\end{array}$ & $\begin{array}{c}\text { Latent } \\
\text { heat flux }\end{array}$ & Temperature & Water vapor & $\begin{array}{l}\text { Sensible } \\
\text { heat flux }\end{array}$ & $\begin{array}{c}\text { Latent } \\
\text { heat flux }\end{array}$ \\
\hline (a) & Residual wind speed & $\begin{array}{c}t-60 \\
t-50 \\
t-40 \\
t-30 \\
t-20 \\
t-10 \\
t\end{array}$ & $\begin{array}{l}-0.10(-0.18) \\
-0.17(-0.26) \\
-0.22(-0.33) \\
-0.28(-0.40) \\
-0.36(-0.50) \\
-0.49(-0.63) \\
-0.62(-\mathbf{0 . 6 9})\end{array}$ & $\begin{array}{c}-0.12(-0.18) \\
-0.09(-0.12) \\
-0.05(-0.03) \\
0.03(0.10) \\
0.15(0.29) \\
0.35(0.54) \\
0.60(\mathbf{0 . 7 0})\end{array}$ & $0.71(0.74)$ & $0.51(0.48)$ & $\begin{array}{l}-0.12(-0.21) \\
-0.18(-0.29) \\
-0.23(-0.35) \\
-0.30(-0.45) \\
-0.41(-0.59) \\
-0.53(-0.69) \\
-\mathbf{0 . 6 4}(-\mathbf{0 . 7 2})\end{array}$ & $\begin{array}{c}-0.05(-0.06) \\
-0.02(0.00) \\
0.02(0.08) \\
0.09(0.22) \\
0.22(0.42) \\
0.39(0.61) \\
0.60(\mathbf{0 . 7 2})\end{array}$ & $0.70(0.75)$ & $0.47(0.45)$ \\
\hline (b) & Total wind speed & $\begin{array}{c}t-60 \\
t-50 \\
t-40 \\
t-30 \\
t-20 \\
t-10 \\
t\end{array}$ & $\begin{array}{l}-0.10(-0.16) \\
-0.15(-0.22) \\
-0.19(-0.28) \\
-0.23(-0.33) \\
-0.27(-0.37) \\
-0.34(-0.42) \\
-0.41(-0.43)\end{array}$ & $\begin{array}{c}-0.07(-0.11) \\
-0.04(-0.05) \\
0.01(0.04) \\
0.06(0.13) \\
0.14(0.25) \\
0.26(0.38) \\
0.40(0.46)\end{array}$ & $0.71(0.69)$ & $0.84(0.85)$ & $\begin{array}{l}-0.13(-0.20) \\
-0.16(-0.23) \\
-0.19(-0.27) \\
-0.23(-0.33) \\
-0.29(-0.40) \\
-0.36(-0.46) \\
-0.42(-0.47)\end{array}$ & $\begin{array}{l}0.00(0.01) \\
0.02(0.05) \\
0.05(0.11) \\
0.10(0.19) \\
0.17(0.29) \\
0.26(0.40) \\
0.38(0.45)\end{array}$ & $0.69(0.69)$ & $0.83(0.85)$ \\
\hline (c) & Temperature & $\begin{array}{c}t-60 \\
t-50 \\
t-40 \\
t-30 \\
t-20 \\
t-10 \\
t\end{array}$ & $1(1)$ & $\begin{array}{c}0.23(0.28) \\
0.16(0.17) \\
0.05(0.02) \\
-0.08(-0.16) \\
-0.26(-0.38) \\
-0.48(-0.61) \\
-\mathbf{0 . 7 0}(-\mathbf{0 . 7 3})\end{array}$ & $\begin{array}{c}0.01(-0.02) \\
-0.08(-0.14) \\
-0.19(-0.29) \\
-0.33(-0.45) \\
-0.51(-0.64) \\
-\mathbf{0 . 7 1}(-\mathbf{0 . 8 4}) \\
-\mathbf{0 . 9 2}(-\mathbf{0 . 9 4})\end{array}$ & $\begin{array}{l}-0.07(-0.11) \\
-0.11(-0.17) \\
-0.15(-0.23) \\
-0.21(-0.30) \\
-0.26(-0.37) \\
-0.33(-0.44) \\
-0.42(-0.48)\end{array}$ & $1(1)$ & $\begin{array}{c}0.12(0.12) \\
0.04(0.00) \\
-0.07(-0.16) \\
-0.21(-0.35) \\
-0.36(-0.53) \\
-0.53(-\mathbf{0 . 6 9}) \\
-\mathbf{0 . 7 1}(-\mathbf{0 . 7 7})\end{array}$ & $\begin{array}{l}-0.07(-0.13) \\
-0.17(-0.26) \\
-0.29(-0.41) \\
-0.43(-0.58) \\
-0.59(-0.75) \\
-\mathbf{0 . 7 6}(-\mathbf{0 . 8 8}) \\
-\mathbf{0 . 9 4}(-\mathbf{0 . 9 6})\end{array}$ & $\begin{array}{l}-0.12(-0.20) \\
-0.16(-0.26) \\
-0.20(-0.31) \\
-0.25(-0.37) \\
-0.31(-0.44) \\
-0.38(-0.50) \\
-0.45(-0.53)\end{array}$ \\
\hline (d) & Water vapor & $\begin{array}{c}t-60 \\
t-50 \\
t-40 \\
t-30 \\
t-20 \\
t-10 \\
t\end{array}$ & $\begin{array}{l}-0.25(-0.35) \\
-0.30(-0.41) \\
-0.35(-0.47) \\
-0.42(-0.56) \\
-0.51(-0.65) \\
-0.61(-\mathbf{0 . 7 3}) \\
-\mathbf{0 . 7 0}(-\mathbf{0 . 7 3})\end{array}$ & $1(1)$ & $\begin{array}{l}0.17(0.26) \\
0.22(0.33) \\
0.27(0.39) \\
0.34(0.48) \\
0.44(0.59) \\
0.56(\mathbf{0 . 6 9 )} \\
\mathbf{0 . 6 6}(\mathbf{0 . 7 2})\end{array}$ & $\begin{array}{l}0.11(0.20) \\
0.13(0.22) \\
0.13(0.21) \\
0.13(0.20) \\
0.11(0.18) \\
0.09(0.16) \\
0.04(0.14)\end{array}$ & $\begin{array}{l}-0.30(-0.43) \\
-0.34(-0.48) \\
-0.40(-0.55) \\
-0.47(-0.62) \\
-0.56(-0.71) \\
-0.63(-\mathbf{0 . 7 6}) \\
-\mathbf{0 . 7 1}(-\mathbf{0 . 7 7})\end{array}$ & $1(1)$ & $\begin{array}{l}0.24(0.37) \\
0.28(0.42) \\
0.33(0.48) \\
0.40(0.55) \\
0.49(0.65) \\
0.58(\mathbf{0 . 7 2}) \\
\mathbf{0 . 6 7}(\mathbf{0 . 7 4})\end{array}$ & $\begin{array}{l}0.14(0.26) \\
0.14(0.25) \\
0.14(0.24) \\
0.13(0.22) \\
0.12(0.21) \\
0.09(0.19) \\
0.03(0.17)\end{array}$ \\
\hline
\end{tabular}

water path and rain water path, the two constituents of liquid water path, with surface temperature and sensible heat flux, illustrates a noteworthy manifestation of cloud microphysics: the lag at which the correlation of cloud water path with surface air temperature and surface sensible heat flux becomes extremal is $\approx 30 \mathrm{~min}$ (Table $3 \mathrm{~d}$ ). The lag is shorter, with $\approx 20 \mathrm{~min}$, for the rain water path (Table 3e). Hence, cloud water predicts the distribution of surface air temperature and surface sensible heat flux with a greater lead time than rain water; this is because rain water first needs to form from cloud water by collision-coalescence. The distribution of rain water path and the delayed distribution of surface air temperature is shown in Fig. 11c (Supplement, Fig. A-3c after filtering), with the open-cell structure clearly visible.

In summary, based on lagged spatial correlation analysis, cloud formation, cloud optical depth and liquid water path, and cloud and rain water path are good predictors of the spatial distribution of surface air temperature and sensible heat flux in the open-cell state, but not of surface water vapor and surface latent heat flux. As a consequence of the causal chain of latent heat release in cloud-forming updrafts, the associated buildup of liquid water path and cloud optical depth, formation of cloud droplets and subsequently of rain droplets, these quantities predict surface air temperature and sensi- ble heat flux with lead times decreasing from $\approx 40 \mathrm{~min}$ to $\approx 20 \mathrm{~min}$. These lead times are subject to some uncertainty, owing to the temporal resolution of $10 \mathrm{~min}$ at which the simulation data were sampled.

\subsection{Maintenance of the open-cell state}

It will be demonstrated that the open-cell state in simulation $\mathcal{S}_{\circ}$ creates surface heat fluxes, specifically a surface sensible heat flux, by which it is maintained. To this end, simulation $\mathcal{S}_{\otimes}$ was conducted, which has a setup that is identical to the open-cell simulation $\mathcal{S}_{\circ}$, except that $\mathcal{S}_{\otimes}$ is forced with spatially homogenized surface fluxes of sensible heat, latent heat, and sea salt from the closed-cell simulation $\mathcal{S}_{\text {}}$. The cloud structure in simulation $\mathcal{S}_{\otimes}$ is shown in Fig. 12; Fig. 13 compares time series of selected quantities in simulation $\mathcal{S}_{\otimes}$ and $\mathcal{S}_{\circ}$. Simulation $\mathcal{S}_{\otimes}$ develops an open-cell state which is present after $12 \mathrm{~h}$ (Fig. 12a). This open-cell state does not endure; after $36 \mathrm{~h}$ (Fig. 12b) it has been replaced by a state that exhibits numerous localized cloud features, reminiscent of a field of shallow cumuli. Cloud fraction (Fig. 13a) is slightly higher, and liquid water path (Fig. 13b) and surface rain (Fig. 13c) are notably enhanced in simulation $\mathcal{S}_{\otimes}$ relative to $\mathcal{S}_{\mathrm{o}}$. Hence, when used to drive the open-cell state, 
Table 3. Lagged spatial correlation coefficients of surface quantities and vertically integrated cloud properties in simulation $\mathcal{S}_{\circ}$. Correlation coefficients with an absolute value $\geq 0.66$ are highlighted in bold. Correlation coefficients in parentheses were calculated from data after filtering with a circular low-pass filter with a diameter of $4500 \mathrm{~m}$.

\begin{tabular}{|c|c|c|c|c|c|c|c|c|c|c|}
\hline & & \multirow[b]{2}{*}{$\begin{array}{l}\text { Time } \\
(\mathrm{min})\end{array}$} & \multicolumn{4}{|c|}{$t=11$ July $200121: 00: 00$ UT } & \multicolumn{4}{|c|}{$t=12$ July 2001 06:00:00 UT } \\
\hline & & & Temperature & Water vapor & $\begin{array}{l}\text { Sensible } \\
\text { heat flux }\end{array}$ & $\begin{array}{c}\text { Latent } \\
\text { heat flux }\end{array}$ & Temperature & Water vapor & $\begin{array}{l}\text { Sensible } \\
\text { heat flux }\end{array}$ & $\begin{array}{c}\text { Latent } \\
\text { heat flux }\end{array}$ \\
\hline \multirow{7}{*}{ (a) } & \multirow{7}{*}{ Latent heat release path } & $t-60$ & $-0.20(-0.58)$ & $0.03(0.16)$ & $0.15(0.49)$ & $0.08(0.30)$ & $-0.22(-0.65)$ & $0.06(0.29)$ & $0.18(0.58)$ & $0.10(0.38)$ \\
\hline & & $t-50$ & $-0.24(-0.66)$ & $0.05(0.25)$ & $0.19(0.58)$ & $0.10(0.35)$ & $-0.27(-\mathbf{0 . 7 2})$ & $0.09(0.35)$ & $0.22(0.65)$ & $0.11(0.42)$ \\
\hline & & $t-40$ & $-0.28(-\mathbf{0 . 7 1})$ & $0.08(0.32)$ & $0.22(0.65)$ & $0.11(0.39)$ & $-0.29(-\mathbf{0 . 7 4})$ & $0.10(0.40)$ & $0.24(\mathbf{0 . 7 0})$ & $0.13(0.45)$ \\
\hline & & $t-30$ & $-0.29(-\mathbf{0 . 7 0})$ & $0.10(0.36)$ & $0.25(\mathbf{0 . 6 6 )}$ & $0.14(0.41)$ & $-0.30(-\mathbf{0 . 7 2})$ & $0.11(0.43)$ & $0.26(\mathbf{0 . 6 9 )}$ & $0.15(0.45)$ \\
\hline & & $t-20$ & $-0.26(-0.61)$ & $0.12(0.39)$ & $0.24(0.59)$ & $0.14(0.35)$ & $-0.27(-0.65)$ & $0.13(0.45)$ & $0.25(0.64)$ & $0.15(0.41)$ \\
\hline & & $t-10$ & $-0.20(-0.48)$ & $0.14(0.39)$ & $0.20(0.48)$ & $0.11(0.26)$ & $-0.23(-0.55)$ & $0.15(0.44)$ & $0.22(0.55)$ & $0.13(0.34)$ \\
\hline & & $t$ & $-0.12(-0.33)$ & $0.15(0.37)$ & $0.11(0.34)$ & $0.01(0.16)$ & $-0.15(-0.42)$ & $0.17(0.41)$ & $0.15(0.43)$ & $0.05(0.24)$ \\
\hline \multirow{7}{*}{ (b) } & \multirow{7}{*}{ Cloud optical depth } & $t-60$ & $-0.26(-0.49)$ & $-0.03(0.02)$ & $0.19(0.39)$ & $0.13(0.30)$ & $-0.30(-0.56)$ & $0.04(0.17)$ & $0.24(0.49)$ & $0.16(0.37)$ \\
\hline & & $t-50$ & $-0.34(-0.61)$ & $0.02(0.13)$ & $0.26(0.52)$ & $0.16(0.35)$ & $-0.38(-\mathbf{0 . 6 8})$ & $0.09(0.28)$ & $0.31(0.61)$ & $0.19(0.42)$ \\
\hline & & $t-40$ & $-0.43(-0.71)$ & $0.08(0.24)$ & $0.34(0.63)$ & $0.19(0.41)$ & $-0.46(-\mathbf{0 . 7 6})$ & $0.14(0.36)$ & $0.38(\mathbf{0 . 7 0})$ & $0.22(0.47)$ \\
\hline & & $t-30$ & $-0.48(-\mathbf{0 . 7 6})$ & $0.13(0.32)$ & $0.40(\mathbf{0 . 6 9 )}$ & $0.23(0.44)$ & $-0.51(-\mathbf{0 . 8 0})$ & $0.18(0.43)$ & $0.44(\mathbf{0 . 7 5})$ & $0.25(0.49)$ \\
\hline & & $t-20$ & $-0.48(-\mathbf{0 . 7 4})$ & $0.17(0.39)$ & $0.42(\mathbf{0 . 7 0})$ & $0.25(0.42)$ & $-0.52(-0.79)$ & $0.21(0.48)$ & $0.46(\mathbf{0 . 7 5})$ & $0.26(0.48)$ \\
\hline & & $t-10$ & $-0.44(-\mathbf{0 . 6 7})$ & $0.22(0.43)$ & $0.40(0.64)$ & $0.22(0.37)$ & $-0.50(-\mathbf{0 . 7 4})$ & $0.25(0.50)$ & $0.45(\mathbf{0 . 7 2})$ & $0.26(0.45)$ \\
\hline & & $t$ & $-0.36(-0.56)$ & $0.24(0.43)$ & $0.33(0.55)$ & $0.15(0.29)$ & $-0.42(-0.65)$ & $0.27(0.50)$ & $0.39(0.64)$ & $0.21(0.38)$ \\
\hline \multirow{7}{*}{ (c) } & \multirow{7}{*}{ Liquid water path } & & $-0.23(-0.41)$ & $-0.06(-0.03)$ & $0.16(0.32)$ & 26) & $-0.27(-0.49)$ & 2) & 0.21 & 0.16 \\
\hline & & $t-50$ & $-0.33(-0.55)$ & $0.00(0.08)$ & $0.25(0.45)$ & $0.17(0.32)$ & $-0.37(-0.63)$ & $0.08(0.24)$ & $0.30(0.56)$ & $0.19(0.39)$ \\
\hline & & $t-40$ & $-0.43(-\mathbf{0 . 6 6})$ & $0.07(0.20)$ & $0.34(0.58)$ & $0.20(0.37)$ & $-0.47(-\mathbf{0 . 7 3})$ & $0.14(0.34)$ & 0.39 (0.66) & $0.23(0.44)$ \\
\hline & & $t-30$ & $-0.51(-\mathbf{0 . 7 4})$ & $0.13(0.29)$ & $0.41(\mathbf{0 . 6 6 )}$ & $0.23(0.40)$ & $-0.54(-\mathbf{0 . 7 9})$ & $0.18(0.41)$ & $0.45(\mathbf{0 . 7 3})$ & $0.25(0.47)$ \\
\hline & & $t-20$ & $-0.55(-\mathbf{0 . 7 5})$ & $0.18(0.36)$ & $0.46(\mathbf{0 . 6 9 )}$ & $0.25(0.40)$ & $-0.57(-\mathbf{0 . 8 0})$ & $0.21(0.46)$ & $0.49(\mathbf{0 . 7 6})$ & $0.27(0.48)$ \\
\hline & & $t-10$ & $-0.53(-0.72)$ & $0.22(0.40)$ & 0.45 (0.67) & $0.23(0.37)$ & $-0.55(-\mathbf{0 . 7 6})$ & $0.25(0.48)$ & $0.49(\mathbf{0 . 7 3})$ & $0.27(0.45)$ \\
\hline & & $t$ & $-0.45(-\mathbf{0 . 6 2})$ & $0.25(0.42)$ & $0.40(0.59)$ & $0.18(0.31)$ & $-0.48(-\mathbf{0 . 6 8})$ & $0.27(0.48)$ & 0.44 (0.66) & $0.23(0.39)$ \\
\hline \multirow{7}{*}{ (d) } & \multirow{7}{*}{ Cloud water path } & $t-60$ & $-0.24(-0.55)$ & $0.01(0.10)$ & $0.17(0.45)$ & $0.11(0.30)$ & $-0.27(-0.62)$ & $0.07(0.24)$ & $0.22(0.55)$ & $0.13(0.38)$ \\
\hline & & $t-50$ & $-0.29(-0.63)$ & $0.05(0.19)$ & $0.22(0.55)$ & $0.12(0.35)$ & $-0.33(-\mathbf{0 . 7 0})$ & $0.10(0.32)$ & $0.26(0.64)$ & $0.14(0.42)$ \\
\hline & & $t-40$ & $-0.35(-\mathbf{0 . 7 1})$ & $0.09(0.29)$ & $0.28(0.64)$ & $0.15(0.40)$ & $-0.37(-\mathbf{0 . 7 5})$ & $0.12(0.38)$ & 0.31 (0.69) & $0.17(0.46)$ \\
\hline & & $t-30$ & $-0.37(-\mathbf{0 . 7 2})$ & $0.11(0.34)$ & $0.32(\mathbf{0 . 6 7})$ & $0.19(0.44)$ & $-0.38(-\mathbf{0 . 7 5})$ & $0.14(0.43)$ & $0.33(\mathbf{0 . 7 1})$ & $0.19(0.47)$ \\
\hline & & $t-20$ & $-0.34(-0.65)$ & $0.14(0.38)$ & $0.31(0.63)$ & $0.20(0.40)$ & $-0.36(-\mathbf{0 . 7 0})$ & $0.17(0.46)$ & $0.33(\mathbf{0 . 6 8})$ & $0.20(0.44)$ \\
\hline & & $t-10$ & $-0.28(-0.54)$ & $0.17(0.40)$ & $0.27(0.53)$ & $0.16(0.31)$ & $-0.33(-0.63)$ & $0.20(0.47)$ & $0.32(0.62)$ & $0.20(0.39)$ \\
\hline & & $t$ & $-0.20(-0.41)$ & $0.19(0.40)$ & $0.20(0.42)$ & $0.09(0.22)$ & $-0.25(-0.52)$ & $0.21(0.46)$ & $0.25(0.52)$ & $0.13(0.31)$ \\
\hline \multirow{7}{*}{ (e) } & \multirow{7}{*}{ Rain water path } & $t-60$ & $-0.17(-0.33)$ & $-0.09(-0.08)$ & $0.12(0.24)$ & $0.12(0.23)$ & $-0.22(-0.41)$ & $-0.02(0.06)$ & $0.17(0.35)$ & $0.15(0.30)$ \\
\hline & & $t-50$ & $-0.27(-0.47)$ & $-0.03(0.04)$ & $0.20(0.38)$ & $0.15(0.28)$ & $-0.33(-0.57)$ & $0.05(0.20)$ & $0.27(0.50)$ & $0.18(0.36)$ \\
\hline & & $t-40$ & $-0.38(-0.60)$ & $0.04(0.15)$ & $0.29(0.51)$ & $0.18(0.33)$ & $-0.43(-\mathbf{0 . 6 9})$ & $0.12(0.30)$ & $0.36(0.62)$ & $0.21(0.41)$ \\
\hline & & $t-30$ & $-0.47(-\mathbf{0 . 6 9})$ & $0.11(0.26)$ & $0.37(0.61)$ & $0.20(0.36)$ & $-0.51(-\mathbf{0 . 7 6})$ & $0.16(0.38)$ & $0.43(\mathbf{0 . 7 0})$ & $0.23(0.45)$ \\
\hline & & $t-20$ & $-0.53(-\mathbf{0 . 7 3})$ & $0.15(0.33)$ & $0.43(\mathbf{0 . 6 6 )}$ & $0.22(0.37)$ & $-0.55(-\mathbf{0 . 7 9})$ & $0.19(0.43)$ & $0.47(\mathbf{0 . 7 4})$ & $0.25(0.46)$ \\
\hline & & $t-10$ & $-0.54(-0.72)$ & $0.19(0.37)$ & 0.45 (0.66) & $0.22(0.37)$ & $-0.55(-0.77)$ & $0.23(0.46)$ & $0.47(\mathbf{0 . 7 3})$ & $0.25(0.45)$ \\
\hline & & $t$ & $-0.48(-0.65)$ & $0.22(0.40)$ & $0.41(0.61)$ & $0.19(0.32)$ & $-0.49(-\mathbf{0 . 6 9})$ & $0.25(0.47)$ & $0.44(\mathbf{0 . 6 7 )}$ & $0.24(0.40)$ \\
\hline
\end{tabular}

the closed-cell state surface fluxes promote rain formation and surface rain, and are unable to maintain the open-cell state. This raises the question as to which of the open-cell surface fluxes from simulation $\mathcal{S}_{\circ}$ - sensible heat, latent heat, or sea salt - is required or sufficient for the maintenance of the open-cell state. The enhanced sensible heat flux in $\mathcal{S}_{\circ}$ (Fig. 13d) may warm updrafts, or the enhanced sea salt flux (Fig. 13f) could supply condensation nuclei for cloud formation - either of which may prevent the the increase in surface rain seen in simulation $\mathcal{S}_{\otimes}$ (Fig. $13 \mathrm{c}$ ). To elucidate this matter, simulations $\mathcal{S}_{\circ}^{\prime}$ and $\mathcal{S}_{\circ}^{\prime \prime}$ were conducted (Table 1).

The setup of simulation $\mathcal{S}_{\circ}^{\prime}$ differs from that of $\mathcal{S}_{\circ}$ in that sea salt emissions are disabled. $\mathcal{S}_{\circ}^{\prime}$ produces an open-cell state much like $\mathcal{S}_{\circ}$, with nearly indistinguishable time series of cloud fraction, cloud optical depth, liquid water path, and surface rain (Supplement, Sect. B). Hence, the initial aerosol concentration in $\mathcal{S}_{\circ}$ is not depleted by surface rain to a level at which sea salt emissions would be requisite to supply condensation nuclei, and the sea salt flux enhancement in $\mathcal{S}_{\circ}$ rel- ative to $\mathcal{S}_{\boldsymbol{B}}$ is not required to maintain the open-cell state. The argument is complemented by the fact that in $\mathcal{S}_{\otimes}$, despite higher surface rain, the total aerosol concentration is higher than in $\mathcal{S}_{\circ}$ (Fig. 13c, j).

The setup of simulation $\mathcal{S}_{\circ}^{\prime \prime}$ differs from that of $\mathcal{S}_{\circ}$ in that the spatially homogenized surface latent and sea salt flux from the closed-cell simulation $\mathcal{S}_{\bullet}$, and the spatially homogenized surface sensible heat flux from the open-cell simulation $\mathcal{S}_{\circ}$ are used. The open-cell state is maintained in $\mathcal{S}_{\circ}^{\prime \prime}$, and time series of cloud fraction, cloud optical depth, liquid water path and other quantities exhibit no appreciable difference to $\mathcal{S}_{\circ}$, with the exception of a mild enhancement of surface rain (Supplement, Sect. C). The open-cell surface sensible heat flux by itself is hence able to maintain the open-cell state of simulation $\mathcal{S}_{\circ}$.

This completes the task of showing that the open-cell state in simulation $\mathcal{S}_{\circ}$ is maintained by the surface sensible heat flux that it creates. However, several points surrounding this finding deserve attention and will be discussed in 

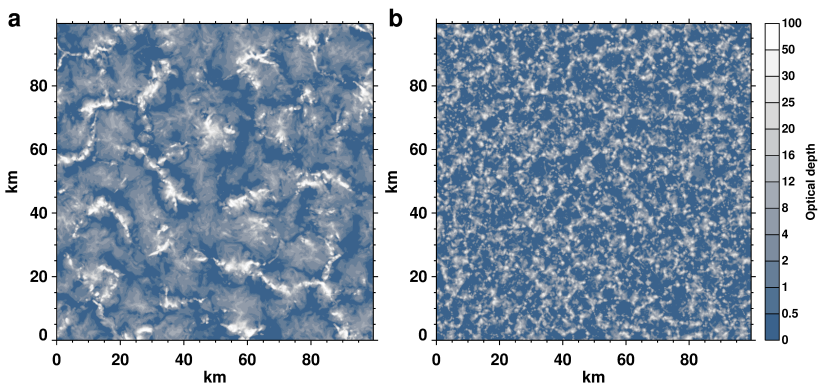

Fig. 12. Cloud optical depth in simulation $\mathcal{S}_{\otimes}$ after $12 \mathrm{~h}$ (a) and $36 \mathrm{~h}(\mathbf{b})$.

the following. Wang et al. (2010) determined that a source of aerosol, such as sea salt emissions, is required to maintain the open-cell state to compensate for aerosol removal by surface rain, and that without such a source, the boundary layer may collapse. This is not in contradiction to the above finding that in the simulation $\mathcal{S}_{\circ}$, sea salt emissions matter not; the reason is that in the present simulations, unlike those in Wang et al. (2010), surface rain does not deplete aerosol to a level at which a source would be required for its replenishment. Nonetheless, sea salt emissions are amplified by up to a factor of eight in the open-cell simulation $\mathcal{S}_{\circ}$ compared to the closed-cell simulation $\mathcal{S}_{\bullet}$ (Fig. 3f). Although in the present simulations, this enhancement plays no role in the evolution of the open-cell state, and notwithstanding the transient nature of the enhancement, we conjecture that in conditions that are more depleted in aerosol, it could contribute to the replenishment of aerosol removed by surface rain. In other words, in such conditions, the open-cell state would create both a surface sensible heat and sea salt flux by which it is maintained.

In what follows, the evolution of the simulation $\mathcal{S}_{\otimes}$ will be analyzed, and an explanation for the decay of its opencell state will be given. Most insight is gained by examination of surface air temperature, surface water vapor and the condensation level (Fig. 13g-i). Simulation $\mathcal{S}_{\otimes}$ has a cooler (Fig. 13g) and more humid (Fig. 13h) surface layer than $\mathcal{S}_{\circ}$. This is a consequence of the lower sensible heat flux (Fig. 13d), likely in conjunction with more cooling and humidification below cloud base due to higher evaporation accompanying enhanced surface rain (Fig. 13c). The surface latent heat flux is lower in the initial $16 \mathrm{~h}$ of simulation $\mathcal{S}_{\otimes}$ compared to $\mathcal{S}_{0}$, and therefore can not readily explain the more humid surface layer in $\mathcal{S}_{\otimes}$. The cooler and more humid surface layer gives rise to cooler and more humid updrafts, wherein water vapor saturates at a lower altitude, illustrated by a lower condensation level (Fig. 13i). The result is an increased liquid water path (Fig. 13b) and a higher surface rain rate (Fig. 13c). It is central to the understanding of the decay of the open-cell state in simulation $\mathcal{S}_{\otimes}$ that this higher surface rain rate is accompanied by an increase in the number a

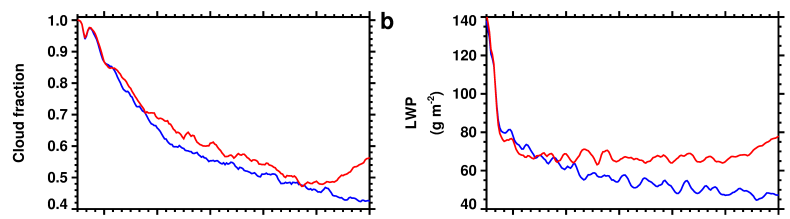

c
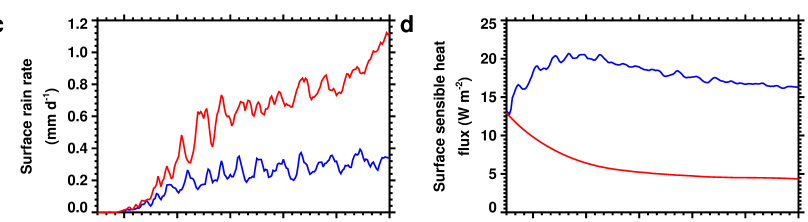

e
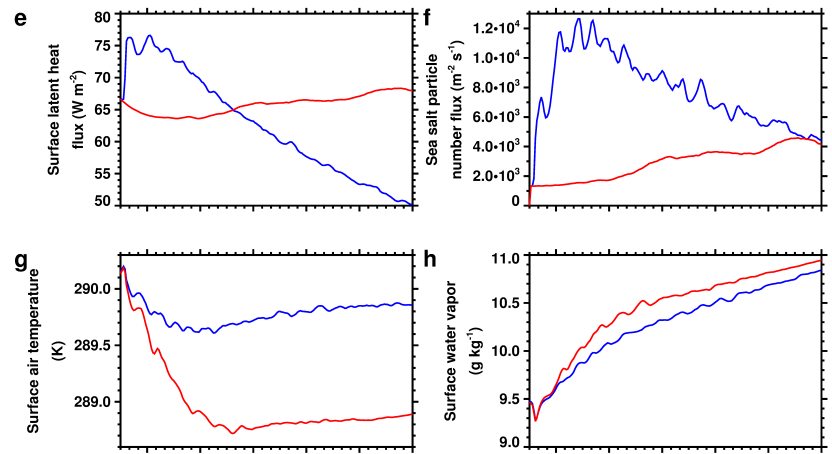

i
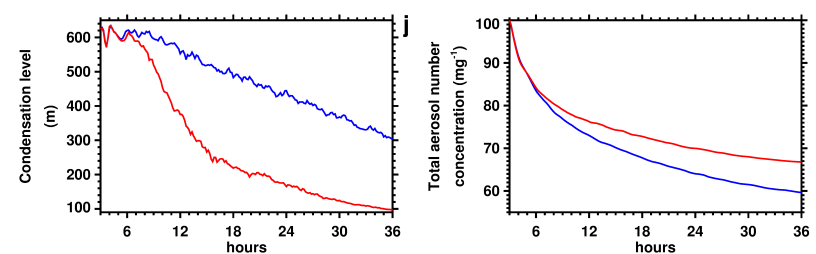

Fig. 13. Domain-averaged time series of selected quantities in simulation $\mathcal{S}_{\circ}$ (blue) and $\mathcal{S}_{\otimes}$ (red).

of rain regions, and by a change in the vertical distribution of thermal forcing in the boundary layer, as will be shown next.

A numerical algorithm was used to identify contiguous regions larger than a given size $\left(\geq 1 \mathrm{~km}^{2}\right)$ with surface rain rates exceeding a given threshold $\left(\geq 1 \mathrm{~mm} \mathrm{~d}^{-1}\right)$. The number of rain locations increases in simulation $\mathcal{S}_{\otimes}$ compared to simulation $\mathcal{S}_{\circ}$, most dramatically in the last $8 \mathrm{~h}$ of the simulation (Fig. 14). The increase arises as open-cell walls, which form at convergence zones of two adjacent cells, produce surface rain in addition to the convergence zones of three adjacent cells (Feingold et al., 2010), owing to the cooler and more humid surface layer in $\mathcal{S}_{\otimes}$. In contrast, surface rain in simulation $\mathcal{S}_{\circ}$ is largely limited to the convergence zones of three adjacent cells, which constitute future open-cell centers. The increased propensity to precipitate causes the collapse of the open-cell state in simulation $\mathcal{S}_{\otimes}$, as it spawns an ever-increasing number of potential future cell centers, while cell walls disappear. With the onset of the runaway multiplication of rain locations (24-32 h of the simulation), a change in the vertical distribution of thermal forcing takes place in $\mathcal{S}_{\otimes}$ (Fig. 15): downdrafts lose thermal forcing by cloud top 


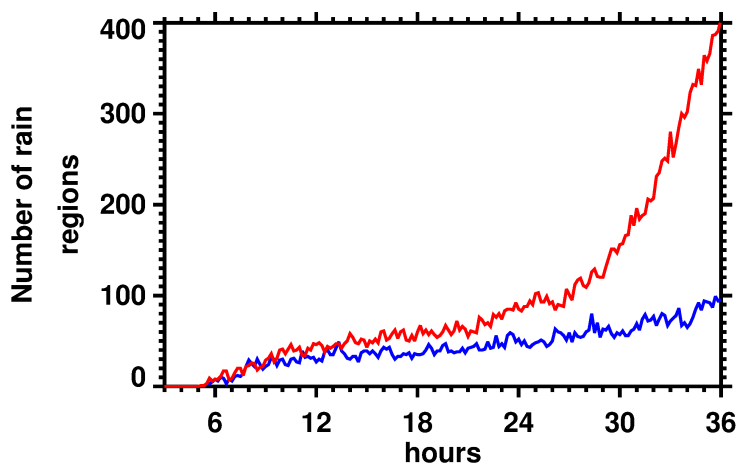

Fig. 14. Temporal evolution of the number of rain regions $\geq 1 \mathrm{~km}^{2}$, with a surface rain rate $\geq 1 \mathrm{~mm} \mathrm{~d}^{-1}$, in simulation $\mathcal{S}_{\circ}$ (blue) and $\mathcal{S}_{\otimes}($ red $)$.

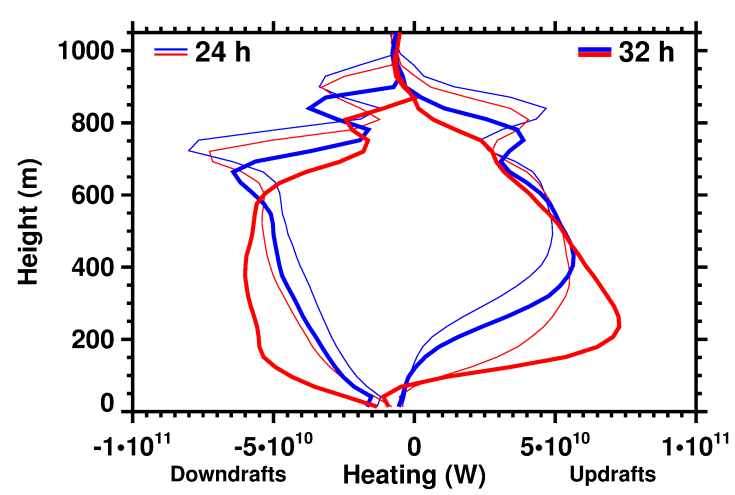

Fig. 15. Total heating (latent + long-wave) in downdrafts (left) and updrafts (right), after $24 \mathrm{~h}$ (thin curves) and $32 \mathrm{~h}$ (thick curves) in simulation $\mathcal{S}_{\circ}$ (blue) and $\mathcal{S}_{\otimes}$ (red).

cooling (characteristic of stratiform cloud elements), and assume a more cumuliform thermal forcing, dominated by contributions from the lower and middle boundary layer. In contrast, the open-cell state in simulation $\mathcal{S}_{\circ}$ maintains forcing of downdrafts by cloud top cooling.

Lewellen et al. (1996) investigated the differences between (non-precipitating) stratocumulus clouds with different forcing by surface latent versus sensible heat flux. At a reduced Bowen ratio (corresponding to a reduced sensible heat flux or increased latent heat flux), they found that the boundary layer becomes more surface driven, and develops a greater horizontal heterogeneity in liquid water path with significant local liquid water path enhancements. This is qualitatively consistent with the behavior seen in simulation $\mathcal{S}_{\otimes}$ (Fig. 13): a steady decrease in the Bowen ratio increases the liquid water path, leads to enhanced collision-coalescence and to the formation of rain at more locations. This is accompanied by a change in heating profiles that become more cumuliform (Fig. 15) with the runaway multiplication of rain locations (Fig. 14).

The runaway multiplication of rain locations also results in a desynchronization of the system: the open-cell state in
$\mathcal{S}_{\otimes}$ initially exhibits domain-wide oscillations of cloud formation (diagnosed by the latent heat release path), liquid water path, and surface rain (Fig. 16), as seen in simulation $\mathcal{S}_{\circ}$ (Fig. 6). However, in the final hours of $\mathcal{S}_{\otimes}$, as the number of rain locations increases most dramatically, the amplitude of the oscillations fades away. This indicates that cloud formation and surface rain proceed more independently at the different locations of the domain.

To complete the discussion of the maintenance of the precipitating open-cell state, the open problem of its stability and the reasons for its relevance shall be briefly noted. Figure $3 \mathrm{~d}-\mathrm{f}$ shows that once they have peaked, the surface fluxes of sensible and latent heat as well as of sea salt aerosol in simulation $\mathcal{S}_{\circ}$ continuously decrease. Even though it was shown that the open-cell state in simulation $\mathcal{S}_{\circ}$ creates surface fluxes required for its maintenance, this decrease with time raises the question of whether and in what conditions the open-cell state can attain a steady state, and thereby maintain itself indefinitely, or whether, in what conditions, and how quickly the continuous decrease in the surface fluxes causes its downfall. Prima facie, this question may appear unimportant, because in nature, the open-cell state will be subject to changing environmental conditions and a steady state may never materialize - e.g., the air mass in which the open-cell state is embedded may be advected along a gradient in sea surface temperature, which would change the surface sensible heat flux. This, together with a changing balance between large-scale subsidence and entrainment as geographic location changes, would modify cloud properties and the dynamic state of the boundary layer. However, it is the stability of the open-cell state, or the absence thereof in given conditions, that prevents or enables changes in the environmental conditions to extend or shorten the lifetime of the open-cell state. The question also has merit from a conceptual point of view, in the sense of understanding the extent to which precipitating open-cell cloudiness should be regarded as a potentially stable or a purely transitional marine boundary layer state. These questions will be addressed in future work.

\subsection{The role of surface flux spatial inhomogeneity for the closed- and open-cell state}

It is demonstrated that the spatial distribution of surface fluxes has little bearing on cloud properties in the considered closed- and the open-cell state. To this end, closed- and open-cell simulations were conducted with spatially homogenized surface fluxes from the simulations $\mathcal{S}_{\bullet}$ and $\mathcal{S}_{\circ}$. These are the simulations $\mathcal{S}_{\overline{0}}$ and $\mathcal{S}_{\overline{0}}$, respectively (Table 1). Spatial homogenization of the surface fluxes has no appreciable effect on cloud properties in the closed-cell state: in both $\mathcal{S}_{\text {. }}$ and $\mathcal{S}_{\boldsymbol{0}}$, cloud fraction remains very close to unity and precipitation is absent (not shown), while the liquid water path in $\mathcal{S}_{\mathbf{0}}$ increases occasionally by small amounts relative to $\mathcal{S}_{\boldsymbol{0}}$ (Fig. 17). In the open-cell state, spatial homogenization of the surface fluxes has no systematic effect on cloud fraction, 

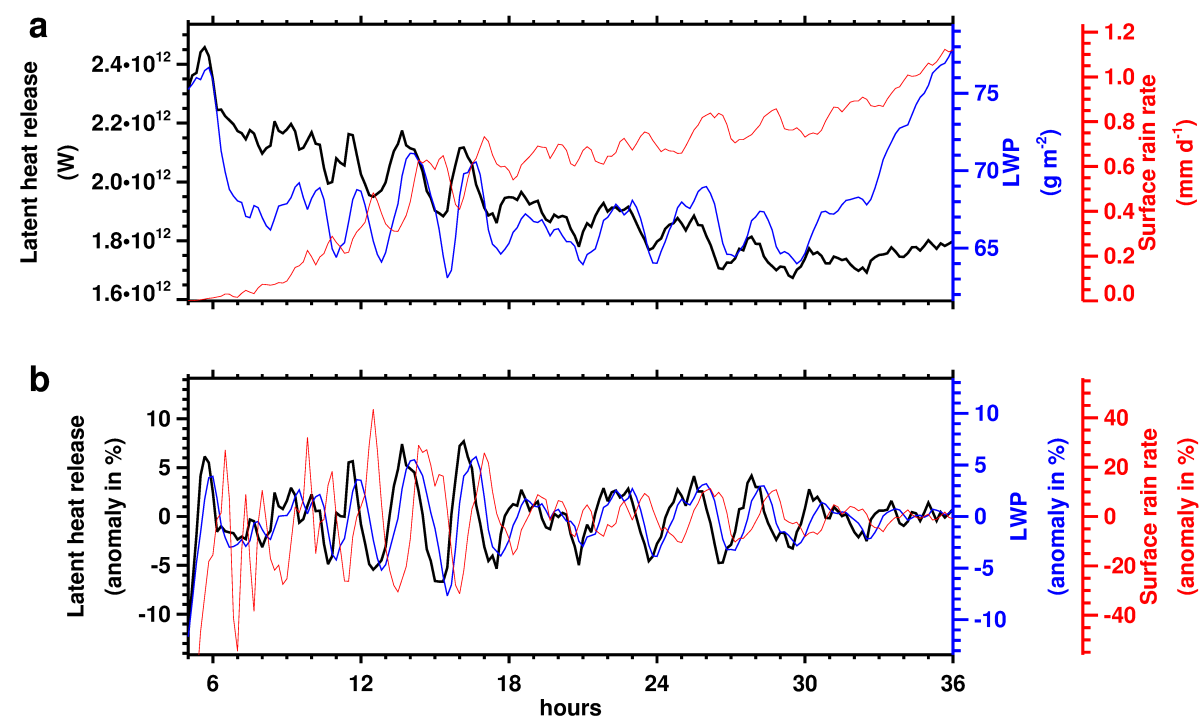

Fig. 16. (a) domain-integrated latent heat release (heating of the air from condensation of water vapor), domain-averaged liquid water path and surface rain, and (b) their temporal anomalies (against a $3 \mathrm{~h}$ running mean) in simulation $\mathcal{S}_{\otimes}$.

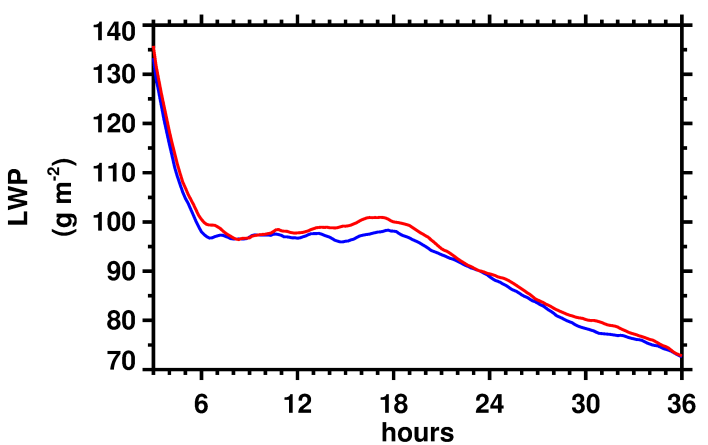

Fig. 17. Domain-averaged time series of liquid water path in simulation $\mathcal{S}_{\bullet}$ (blue) and $\mathcal{S}_{\boldsymbol{\bullet}}$ (red).

liquid water path, and surface rain, and causes only small differences between $\mathcal{S}_{\circ}$ and $\mathcal{S}_{\text {o }}$ (Fig. 18). Seifert and Heus (2013) obtained a similar result for trade wind cumuli: spatial homogenization of surface heat fluxes had only a minor impact in their simulations. A greater sample of simulations to account for variability that exists in the cloudy marine boundary layer would be required for a generalization of this finding beyond the cases considered in this work and by Seifert and Heus (2013).

\subsection{Additional remarks}

The marine boundary layer cellular cloud states considered in this work are specific to the conditions used in the simulations. In nature, the gamut of conditions, processes, and mechanisms not considered in this work and the associated variability in cellular cloudiness may give rise to behavior not captured here. This said, the lack of generality of the ex- amples in this work does not diminish the insight provided into the workings of the cloudy marine boundary layer.

The comparably slow geostrophic wind speed of $\sqrt{2} \mathrm{~m} \mathrm{~s}^{-1}$ used in this work results in only weak surface wind shear and, by consequence, limited shear-induced circulation. This not only leads to a comparably small distortion of the horizontal features in the dynamics and cloud structure, but also to little horizontal shift between features at the boundary layer top and at its base. These benefits of a slow geostrophic wind speed facilitate the spatial correlation analysis conducted here. At higher geostrophic wind speeds, horizontal distortion and shift of spatial features may render such an analysis more demanding or unfeasible, and/or may possibly yield degraded spatial correlation coefficients, although the mechanisms identified in this work may still be in play. It should be noted that at geostrophic wind speeds greater than those used in this work, the total wind speed should become increasingly more important and the residual circulation increasingly less important in driving the surface fluxes.

\section{Conclusions}

A set of idealized cloud system-resolving simulations with the Advanced Research WRF model is presented to give insight into the interaction between marine boundary layer cellular cloudiness and surface fluxes of sensible heat, latent heat, and of sea salt aerosol. The mechanisms responsible for the temporal evolution and spatial distribution of the surface heat fluxes in the non-precipitating closed-cell state and the precipitating open-cell state are investigated and explained. It is found that the closed-cell state imposes its horizontal spatial structure on surface air temperature and water vapor and, 
a

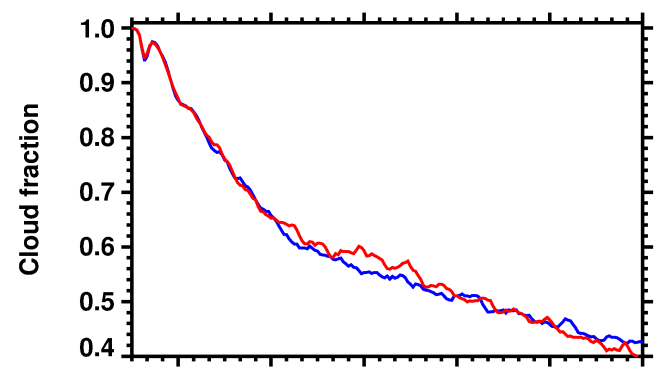

b

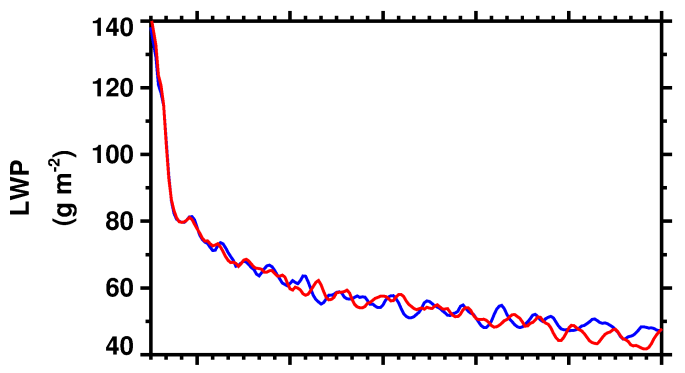

C

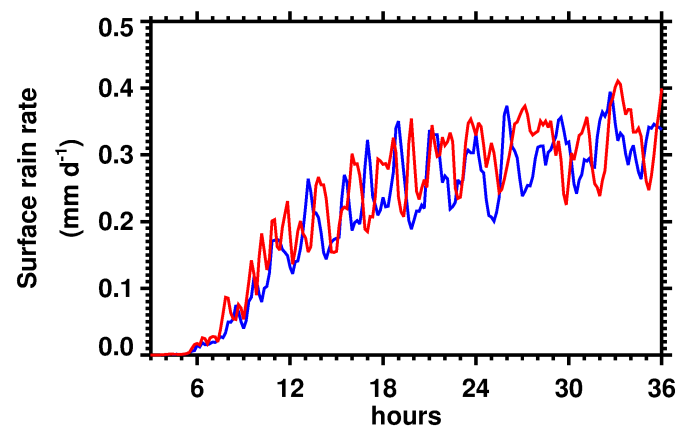

Fig. 18. Domain-averaged time series of selected quantities in simulation $\mathcal{S}_{\circ}$ (blue) and $\mathcal{S}_{\bar{o}}$ (red).

to a lesser degree, on the surface sensible and latent heat flux. The responsible mechanism is the entrainment of dry free tropospheric air into the boundary layer. The open-cell state is associated with oscillations in surface air temperature, water vapor, and in the surface fluxes of sensible heat, latent heat, and of sea salt aerosol. Here, the responsible mechanism is the periodic formation of clouds, rain, and of cold and moist pools with elevated wind speed. Open-cell cloud formation, cloud optical depth and liquid water path, and cloud and rain water path are identified as good predictors of the spatial structure of surface air temperature and sensible heat flux, but not of surface water vapor and latent heat flux. It is shown that the open-cell state creates conditions conducive to its maintenance by enhancing the surface sensible heat flux. The open-cell state also enhances the sea salt flux relative to the closed-cell state. While the open-cell state under consideration is not depleted in aerosol and is insensitive to variations in sea salt fluxes, in aerosol-depleted conditions, the enhancement of the sea salt flux may replenish the aerosol needed for cloud formation and hence contribute to the maintenance of the open-cell state. Furthermore, spatial homogenization of the surface fluxes is found to have only a small effect on cloud properties in the investigated cases.

\section{Supplementary material related to this article is available online at http://www.atmos-chem-phys.net/14/ 61/2014/acp-14-61-2014-supplement.pdf.}

Acknowledgements. The authors wish to thank two anonymous reviewers for their helpful comments. J. Kazil and G. Feingold are supported by the US Department of Energy (DOE) Atmospheric System Research Program grant DE-SC0006972. T. Yamaguchi is supported by the US National Oceanic and Atmospheric Administration (NOAA) Climate Program Office through the Climate Process Team, Cloud Macrophysical Parameterization and its Application to Aerosol Indirect Effects. J. Kazil, G. Feingold, and T. Yamaguchi are supported by NOAA's Climate Goal. Hailong Wang is supported by the DOE Office of Science Earth System Modeling Program. The Pacific Northwest National Laboratory (PNNL) is operated for DOE by Battelle Memorial Institute under contract DE-AC05-76RLO1830. Simulations were carried out on the NOAA Research \& Development High Performance Computing System.

Edited by: R. Wood

\section{References}

Agee, E. M.: Observations from space and thermal convection: a historical perspective, Bull. Am. Meteorol. Soc., 65, 938-949, doi:10.1175/1520-0477(1984)065<0938:OFSATC>2.0.CO;2, 1984.

Atkinson, B. W. and Zhang, J. W.: Mesoscale shallow convection in the atmosphere, Rev. Geophys., 34, 403-431, doi:10.1029/96RG02623, 1996.

Berner, A. H., Bretherton, C. S., and Wood, R.: Large-eddy simulation of mesoscale dynamics and entrainment around a pocket of open cells observed in VOCALS-REx RF06, Atmos. Chem. Phys., 11, 10525-10540, doi:10.5194/acp-11-10525-2011, 2011.

Bretherton, C. S. and Wyant, M. C.: Moisture transport, lowertropospheric stability, and decoupling of cloud-topped boundary layers, J. Atmos. Sci., 54, 148-167, doi:10.1175/15200469(1997)054<0148:MTLTSA>2.0.CO;2, 1997.

Clarke, A. D., Owens, S. R., and Zhou, J.: An ultrafine sea-salt flux from breaking waves: Implications for cloud condensation nuclei in the remote marine atmosphere, J. Geophys. Res., 111, D06202, doi:10.1029/2005JD006565, 2006.

Collins, W. D., Rasch, P. J., Boville, B. A., Hack, J. J., McCaa, J. R., Williamson, D. L., Kiehl, J. T., Briegleb, B., Blitz, C., Lin, S.-J., Zhang, M., and Dai, Y.: Description of the NCAR Community Atmosphere Model (CAM 3.0), Tech. Rep. NCAR/TN464+STR, National Center for Atmospheric Research, Boulder, CO, USA, 2004.

Comstock, K. K., Bretherton, C. S., and Yuter, S. E.: Mesoscale variability and drizzle in Southeast Pacific stratocumulus, J. Atmos. Sci., 62, 3792-3807, doi:10.1175/JAS3567.1, 2005. 
Comstock, K. K., Yuter, S. E., Wood, R., and Bretherton, C. S.: The Three-Dimensional Structure and Kinematics of Drizzling Stratocumulus, Mon. Weather Rev., 135, 3767-3784, doi:10.1175/2007MWR1944.1, 2007.

Deardorff, J. W.: Numerical investigation of neutral and unstable planetary boundary layers, J. Atmos. Sci., 29, 91-115, doi:10.1175/1520-0469(1972)029<0091:NIONAU>2.0.CO;2, 1972.

de Roode, S. R. and Duynkerke, P. G.: Observed Lagrangian transition of stratocumulus into cumulus during ASTEX: Mean state and turbulence structure, J. Atmos. Sci., 54, 2157-2173, doi:10.1175/1520-0469(1997)054<2157:OLTOSI>2.0.CO;2, 1997.

Feingold, G., Koren, I., Wang, H., Xue, H., and Brewer, A. W.: Precipitation-generated oscillations in open cellular cloud fields, Nature, 466, 849-852, doi:10.1038/nature09314, 2010.

Goren, T. and Rosenfeld, D.: Satellite observations of ship emission induced transitions from broken to closed cell marine stratocumulus over large areas, J. Geophys. Res., 117, D17206, doi:10.1029/2012JD017981, 2012.

Grell, G. A., Peckham, S. E., Schmitz, R., McKeen, S. A., Frost, G., Skamarock, W. C., and Eder, B.: Fully coupled "online" chemistry within WRF model, Atmos. Environment, 39, 6957-6975, doi:10.1016/j.atmosenv.2005.04.027, 2005.

Jensen, J., Lee, S., Krummel, P. B., Katzfey, J., and Gogoasa, D.: Precipitation in marine cumulus and stratocumulus - Part I: Thermodynamic and dynamic observations of closed cell circulations and cumulus bands, Atmos. Res., 54, 117-155, doi:doi:10.1016/S0169-8095(00)00040-5, 2000.

Kazil, J., Wang, H., Feingold, G., Clarke, A. D., Snider, J. R., and Bandy, A. R.: Modeling chemical and aerosol processes in the transition from closed to open cells during VOCALS-REx, Atmos. Chem. Phys., 11, 7491-7514, doi:10.5194/acp-11-74912011, 2011.

Koren, I. and Feingold, G.: Adaptive behavior of marine cellular clouds, Sci. Rep., 3, 2507, doi:10.1038/srep02507, 2013.

Krueger, A. F. and Fritz, S.: Cellular cloud patterns revealed by Tiros I, Tellus, 13, 1-7, doi:10.1111/j.21533490.1961.tb00061.x, 1961.

Krueger, S. K., McLean, G. T., and Fu, Q.: Numerical Simulation of the Stratus-to-Cumulus Transition in the Subtropical Marine Boundary Layer, Part I: Boundary-Layer Structure, J. Atmos. Sci., 52, 2839-2850, doi:10.1175/15200469(1995)052<2839:NSOTST>2.0.CO;2, 1995.

Lewellen, D. C., Lewellen, W. S., and Yoh, S.: Influence of Bowen ratio on boundary-layer cloud structure, J. Atmos. Sci., 53, 175-187, doi:10.1175/15200469(1996)053<0175:IOBROB>2.0.CO;2, 1996.

Mechem, D. B., Yuter, S. E., and de Szoeke, S. P.: Thermodynamic and aerosol controls in Southeast Pacific stratocumulus, J. Atmos. Sci., 69, 1250-1266, doi:10.1175/JAS-D-11-0165.1, 2012.

Petters, M. D. and Kreidenweis, S. M.: A single parameter representation of hygroscopic growth and cloud condensation nucleus activity, Atmos. Chem. Phys., 7, 1961-1971, doi:10.5194/acp-71961-2007, 2007.

Randall, D., Krueger, S., Bretherton, C., Curry, J., Duynkerke, P., Moncrieff, M., Ryan, B., Starr, D., Miller, M., Rossow, W., Tselioudis, G., and Wielicki, B.: Confronting models with data -
The GEWEX cloud systems study, B. Am. Meteorol. Soc., 84, 455-469, doi:10.1175/BAMS-84-4-455, 2003.

Rosenfeld, D., Kaufman, Y. J., and Koren, I.: Switching cloud cover and dynamical regimes from open to closed Benard cells in response to the suppression of precipitation by aerosols, Atmos. Chem. Phys., 6, 2503-2511, doi:10.5194/acp-6-2503-2006, 2006.

Savic-Jovcic, V. and Stevens, B.: The structure and mesoscale organization of precipitating stratocumulus, J. Atmos. Sci., 65, 15871605, doi:10.1175/2007JAS2456.1, 2008.

Seifert, A. and Heus, T.: Large-eddy simulation of organized precipitating trade wind cumulus clouds, Atmos. Chem. Phys., 13, 5631-5645, doi:10.5194/acp-13-5631-2013, 2013.

Shao, Q. and Randall, D. A.: Closed mesoscale cellular convection driven by cloud-top radiative cooling, J. Atmos. Sci., 53, 2144-2165, doi:10.1175/15200469(1996)053<2144:CMCCDB>2.0.CO;2, 1996.

Sharon, T. M., Albrecht, B. A., Jonsson, H. H., Minnis, P., Khaiyer, M. M., van Reken, T. M., Seinfeld, J., and Flagan, R.: Aerosol and Cloud Microphysical Characteristics of Rifts and Gradients in Maritime Stratocumulus Clouds, J. Atmos. Sci., 63, 983-997, doi:10.1175/JAS3667.1, 2006.

Skamarock, W. C., Klemp, J. B., Dudhia, J., Gill, D. O., Barker, D. M., Duda, M. G., Huang, X.-Y., Wang, W., and Powers, J. G.: A Description of the Advanced Research WRF Version 3, Tech. Rep. NCAR/TN-475+STR, National Center for Atmospheric Research, Boulder, CO, USA, 2008.

Stevens, B., Lenschow, D. H., Vali, G., Gerber, H., Bandy, A., Blomquist, B., Brenguier, J.-L., Bretherton, C. S., Burnet, F., Campos, T., Chai, S., Faloona, I., Friesen, D., Haimov, S., Laursen, K., Lilly, D. K., Loehrer, S. M., Malinowski, S. P., Morley, B., Petters, M. D., Rogers, D. C., Russell, L., SavicJovcic, V., Snider, J. R., Straub, D., Szumowski, M. J., Takagi, H., Thornton, D. C., Tschudi, M., Twohy, C., Wetzel, M., and van Zanten, M. C.: Dynamics and Chemistry of Marine Stratocumulus-DYCOMS-II, B. Am. Meteorol. Soc., 84, 579593, doi:10.1175/BAMS-84-5-579, 2003.

Stevens, B., Vali, G., Comstock, K., Wood, R., Van Zanten, M. C., Austin, P. H., Bretherton, C. S., and Lenschow, D. H.: Pockets of open cells and drizzle in marine stratocumulus, B. Am. Meteorol. Soc., 86, 51-57, doi:10.1175/BAMS-86-1-51, 2005.

Van Zanten, M. C. and Stevens, B.: Observations of the structure of heavily precipitating marine stratocumulus, J. Atmos. Sci., 62, 4327-4342, doi:10.1175/JAS3611.1, 2005.

Wang, H. and Feingold, G.: Modeling mesoscale cellular structures and drizzle in marine stratocumulus. Part I: impact of drizzle on the formation and evolution of open cells, J. Atmos. Sci., 66, 3237-3256, doi:10.1175/2009JAS3022.1, 2009a.

Wang, H. and Feingold, G.: Modeling mesoscale cellular structures and drizzle in marine stratocumulus, Part II: the microphysics and dynamics of the boundary region between open and closed cells, J. Atmos. Sci., 66, 3257-3275, doi:10.1175/2009JAS3120.1, 2009b.

Wang, H., Feingold, G., Wood, R., and Kazil, J.: Modelling microphysical and meteorological controls on precipitation and cloud cellular structures in Southeast Pacific stratocumulus, Atmos. Chem. Phys., 10, 6347-6362, doi:10.5194/acp-10-6347-2010, 2010. 
Wood, R.: Stratocumulus Clouds, Mon. Weather Rev., 140, $2373-$ 2423, doi:10.1175/MWR-D-11-00121.1, 2012.

Wood, R., Bretherton, C. S., Leon, D., Clarke, A. D., Zuidema, P., Allen, G., and Coe, H.: An aircraft case study of the spatial transition from closed to open mesoscale cellular convection over the Southeast Pacific, Atmos. Chem. Phys., 11, 2341-2370, doi:10.5194/acp-11-2341-2011, 2011.
Xue, H., Feingold, G., and Stevens, B.: Aerosol effects on clouds, precipitation, and the organization of shallow cumulus convection, J. Atmos. Sci., 65, 392-406, doi:10.1175/2007JAS2428.1, 2008. 